\title{
Q.
QNEEN'S
UNIVERSITY
BELFAST
}

\section{Urea-Based Imprinted Polymer Hosts with Switchable Anion Preference}

Shinde, S., Incel, A., Mansour, M., Olsson, G., Nicholls, I., Urraca , J., \& Sellergren, B. (2020). Urea-Based Imprinted Polymer Hosts with Switchable Anion Preference. Journal of the American Chemical Society (JACS), 142(26), 11404-11416. https://doi.org/10.1021/jacs.0c00707

Published in:

Journal of the American Chemical Society (JACS)

Document Version:

Publisher's PDF, also known as Version of record

Queen's University Belfast - Research Portal:

Link to publication record in Queen's University Belfast Research Portal

\section{Publisher rights}

Copyright 2020 the authors.

This is an open access article published under a Creative Commons Attribution License (https://creativecommons.org/licenses/by/4.0/), which permits unrestricted use, distribution and reproduction in any medium, provided the author and source are cited.

\section{General rights}

Copyright for the publications made accessible via the Queen's University Belfast Research Portal is retained by the author(s) and / or other copyright owners and it is a condition of accessing these publications that users recognise and abide by the legal requirements associated with these rights.

Take down policy

The Research Portal is Queen's institutional repository that provides access to Queen's research output. Every effort has been made to ensure that content in the Research Portal does not infringe any person's rights, or applicable UK laws. If you discover content in the Research Portal that you believe breaches copyright or violates any law, please contact openaccess@qub.ac.uk. 


\title{
Urea-Based Imprinted Polymer Hosts with Switchable Anion Preference
}

\author{
Sudhirkumar Shinde, ${ }^{\bigcirc}$ Anil Incel, ${ }^{\bigcirc}$ Mona Mansour, Gustaf D. Olsson, Ian A. Nicholls, Cem Esen, \\ Javier Urraca, and Börje Sellergren*
}

Cite This: J. Am. Chem. Soc. 2020, 142, 11404-11416

Read Online

\section{ACCESS | Llll Metrics \& More | 回 Article Recommendations | (s) Supporting Information}

ABSTRACT: The design of artificial oxyanion receptors with switchable ion preference is a challenging goal in host-guest chemistry. We here report on molecularly imprinted polymers (MIPs) with an external phospho-sulpho switch driven by small molecule modifiers. The polymers were prepared by hydrogen bond-mediated imprinting of the mono- or dianions of phenyl phosphonic acid (PPA), phenyl sulfonic acid (PSA), and benzoic acid (BA) using N-3,5-bis-(trifluoromethyl)-phenyl-Ń-4-vinylphenyl urea (1) as the functional host monomer. The interaction

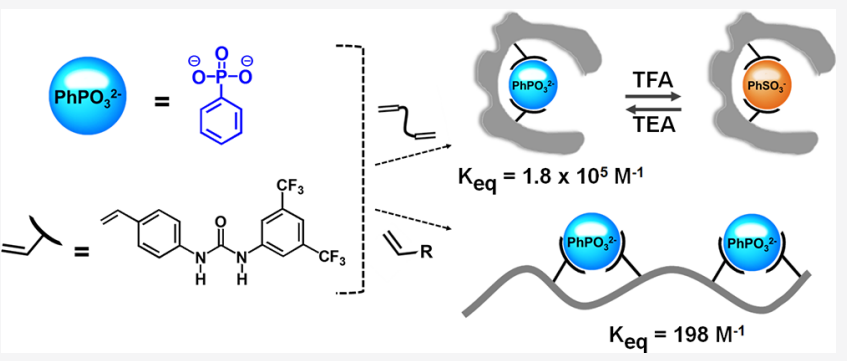
mode between the functional monomer and the monoanions was elucidated by ${ }^{1} \mathrm{H}$ NMR titrations and ${ }^{1} \mathrm{H}-{ }^{1} \mathrm{H}$ NMR NOESY supported by molecular dynamic simulation, which confirmed the presence of high-order complexes. PPA imprinted polymers bound PPA with an equilibrium constant $K_{\mathrm{eq}}=1.8 \times 10^{5} \mathrm{M}^{-1}$ in acetonitrile (0.1\% 1,2,2,6,6-pentamethylpiperidine) and inorganic $\mathrm{HPO}_{4}{ }^{2-}$ and $\mathrm{SO}_{4}{ }^{2-}$ with $K_{\mathrm{eq}}=2.9 \times 10^{3} \mathrm{M}^{-1}$ and $4.5 \times 10^{3} \mathrm{M}^{-1}$, respectively, in aqueous buffer. Moreover, the chromatographic retentivity of phosphonate versus sulfonate was shown to be completely switched on this polymer when changing from a basic to an acidic modifier. Mechanistic insights into this system were obtained from kinetic investigations and DSC-, MALDI-TOF-MS-, ${ }^{1} \mathrm{H}$ NMR-studies of linear polymers prepared in the presence of template. The results suggest the formation of template induced 1-1 diad repeats in the polymer main chain shedding unique light on the relative contributions of configurational and conformational imprinting.

\section{INTRODUCTION}

The molecular constituents of a living cell are predominantly water-soluble molecules carrying a net negative charge, e.g., cofactors, enzyme substrates, nucleic acids, the lipid double layer, and the glycocalix. ${ }^{1-3}$ As a consequence, evolution has resulted in highly refined receptors capable of recognizing anions in water. Some of the most impressive examples are the proteins designed to selectively bind and/or transport either sulfate or phosphate ions. These two pyramidal anions are nearly isosteric with similar molecular volumes and central atom-oxygen bond lengths, whereas they differ with respect to Lewis basicity and hydrophilicity (Table 1 ).

Discrimination between phosphate and sulfate and other isosteric oxyanions (e.g., arsenate) occurs in the sulfate and phosphate binding proteins predominantly through multiple complementary hydrogen bonding (H-bond) interactions involving main chain amides (nests) in a water-poor microenvironment with minor involvement of charge complementary residues. ${ }^{1,4,5}$ Notably, no charged residue is involved in the sulfate binding protein binding site which binds sulfate specifically with an equilibrium binding constant $K_{\mathrm{eq}}=10^{6} \mathrm{M}^{-1}$ in water $(5.0 \leq \mathrm{pH} \leq 8.0),{ }^{5}$ an impressive feat given the strong hydration of this anion. As a consequence, this overturns the Hofmeister series of the salting out tendency for anions which otherwise increases in the order; $\mathrm{CH}_{3} \mathrm{COO}^{-}<\mathrm{HPO}_{4}^{2-}<$ $\mathrm{SO}_{4}{ }^{2-}$.

Inspired by this remarkable performance, much effort has been devoted to the development of neutral sulfate/phosphate binding hosts. ${ }^{4,5}$ In contrast to the more common approach based on charged receptors, neutral hosts can achieve higher selectivity but are challenging to construct since $\mathrm{H}$-bonding is considerably weaker in polar solvents. Nevertheless, both macrocyclic e.g. pyrrole, saphyrine, ${ }^{6}$ peptide $^{7}$ and acyclic podand hosts e.g. ureas, ${ }^{8-11}$ squaramides ${ }^{12-14}$ have been reported showing high sulfate affinity. However, these hosts rarely overturn the Hofmeister solvation governed series of anion affinity especially with respect to the relative preference for phosphate/sulfate. ${ }^{6}$ Moreover, these anion receptors are seldomly capable of switching the anion preference or of binding and releasing the guest upon external stimuli. ${ }^{13}$

Received: January 23, 2020

Published: May 19, 2020 
Table 1. Physical Properties of Sulfate and Phosphate Anions

\begin{tabular}{|c|c|c|c|c|c|}
\hline anion & $\mathrm{p} K_{\mathrm{a}} 1^{a}$ & $\mathrm{p} K_{\mathrm{a}} 2^{a}$ & $\mathrm{p} K_{\mathrm{a}} 3^{a}$ & molecular volume ${ }^{b}\left(\AA^{3}\right)$ & anion hydration energy $^{b}(\mathrm{~kJ} / \mathrm{mol})$ \\
\hline $\mathrm{PO}_{4}{ }^{3-}$ & 2.1 & 7.2 & 10.9 & 56 & -498 \\
\hline $\mathrm{SO}_{4}^{2-}$ & -3 & 1.9 & & 51 & -1130 \\
\hline
\end{tabular}

${ }^{a} \mathrm{p} K_{\mathrm{a}}$ of conjugate acid. ${ }^{b}$ Calculated values assuming $\mathrm{pH}=6$ and an average charge of -2 for sulfate and -1.4 for phosphate. ${ }^{3}$

This highlights a need of neutral hosts with tunable microenvironment capable of alternating phosphate/sulfate recognition. This can in principle be achieved by embedding designed low molecular weight hosts in a polymer scaffold imparting a lower dielectric microenvironment. ${ }^{1}$ Alternatively, a macromolecular host can be designed from simpler building blocks by molecular imprinting. ${ }^{15-20}$ Monomers are here chosen or designed to complement functional groups of a template molecule. Polymerizing the monomer-template complexes into a cross-linked polymer matrix followed by removal of the template, leaves behind sites capable of recognizing the template. This approach benefits from spontaneous self-assembly guiding the binding groups to their positions in the receptor site. Thus, the structure of the final binding site is a priori unknown.

Notable examples of MIPs for anion recognition in water have been reported using both charged, e.g., imidazolium, ${ }^{21-23}$ amidinium, $^{2-27}$ and neutral host monomers, e.g., urea, ${ }^{28-31}$ thiourea, ${ }^{32}$ squaramide, ${ }^{33}$ and others. ${ }^{34}$ Some time ago we introduced urea based host monomers acting as potent $\mathrm{H}$ bond donors for stoichiometric imprinting of oxyanions or other H-bond acceptors. ${ }^{35}$ Receptors for $\beta$-lactam antibiotics, ${ }^{36}$ phospho-peptides, ${ }^{28}$ peptide biomarkers, ${ }^{37}$ phospholipids, ${ }^{22}$ sugar acids, ${ }^{31}$ and sulfated peptides ${ }^{29}$ were demonstrated.

To gain insight into the nature of these imprinted receptors at a molecular level we here report an in-depth investigation of MIPs for simple oxyanions (Scheme 1).

Scheme 1. Plausible Structural Formulas of H-Bonded Complex between Oxyanions and 1,3-Diaryl Urea Monomer 1 (left) and Structures of Oxyacids Used in the Study (Right) ${ }^{a}$
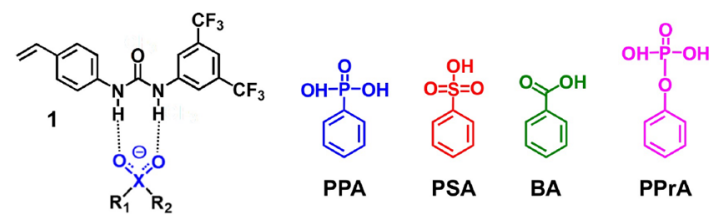

${ }^{a} \mathrm{PPA}=$ phenylphosphonic acid; $\mathrm{PSA}=$ phenylsulfonic acid; $\mathrm{BA}=$ benzoic acid; and PPrA = phenylphosphoric acid.

With this we aimed to answer the following questions: (1) What level of oxyanion selectivity and affinity can be achieved with MIPs in organic and aqueous media? (2) Can MIPs recognize inorganic anions in water? (3) Can the Hofmeister preference be overturned? (4) Can we switch oxyanion preference using the same MIP? (5) What are the mechanisms underlying the imprinting process?

On the basis of combined physical characterization, modeling, spectroscopic studies of prepolymerization complexes, and studies of the polymerization kinetics we here offer answers to the aforementioned questions.

\section{RESULTS AND DISCUSSION}

Monomer/Template Complex Formation. 1,3-Disubstituted ureas have long been exploited as neutral hosts $(\mathrm{H})$ for complexing oxyanion guests $(\mathrm{G}){ }^{38,39}$ They provide a 2 -fold $\mathrm{H}$ bond donor which with the acceptor (e.g. carboxylate, phosphate, sulfate) results in a cyclic H-bonded complex. Also, several structural and compositional parameters can be readily tuned to enhance $\mathrm{HG}$ association strengths (Scheme 2).

\section{Scheme 2. Structural and Compositional Parameters for} Tuning Host-Guest Association Strength ${ }^{a}$

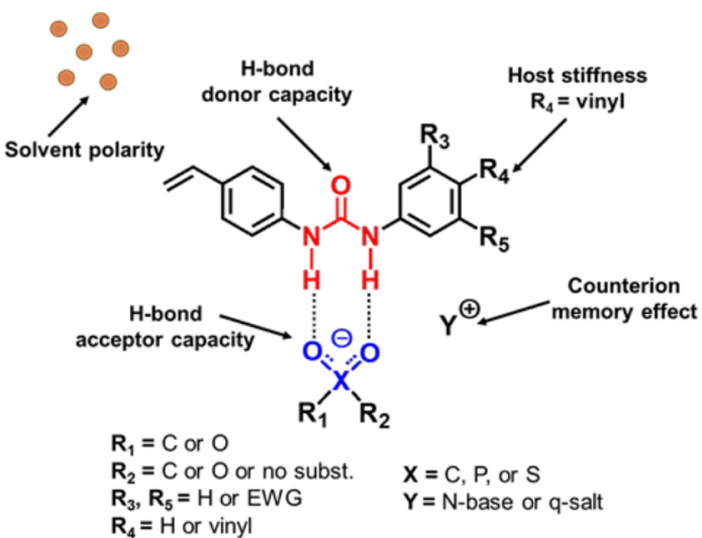

${ }^{a} \mathrm{EWG}=$ electron withdrawing group.

The affinity for the guest increases with the acidity of the urea protons (donor capacity, $\mathrm{R}_{3}, \mathrm{R}_{4}, \mathrm{R}_{5}=$ electron withdrawing groups (EWGs)) and the basicity of the oxyanion (acceptor capacity), but this can be offset by the ability of the host to self-associate and host deprotonation. ${ }^{40}$ The latter leads to nondirectional electrostatic interactions and is promoted by increased solvent polarity. ${ }^{41}$ This is an undesired effect since it undermines the structural integrity of the hydrogen bond connected HG complex-hence a compromise between host acidity and guest basicity has to be found that maximizes the complex strength. In this context, no deprotonation has so far been observed for the host monomer, $\mathbf{1}$, used in the current study (Scheme 1). The nature of the countercation also influences the HG complex stability. Complexation can be easily induced by proton transfer to amine bases but this causes undesirable competition between the urea host and the protonated amine for binding the guest. Stronger complexation is therefore induced by the use of bulky tertiary amines (e.g., pentamethylpiperidine, PMP) or quaternary ammonium ions like tetrabutylammonium (TBA), which have been shown to produce pronounced counterion memory effects. ${ }^{28,42}$ Another factor is the level of host preorganization, which impacts on the size of the entropic penalty upon guest complexation due to the need to freeze internal rotors. For monourea host monomers this can in principle be enhanced by introducing two polymerizable groups (cross-linkers) in the host thereby 
increasing host stiffness $\left(\mathrm{R}_{4}=\right.$ vinyl in Scheme 2$){ }^{41}$ For ternary HG complexes formed from phosphate dianions and urea hosts (2:1 complex in Scheme 3), host preorganization has been enhanced by introducing the cleft-like host monomer $2(1: 1$ complex in Scheme 3$) .^{28}$

Scheme 3. Anticipated Ternary or Binary MonomerTemplate Complexes Formed Using Mono- (Left) Or Di(Right) Functional Urea Host Monomers
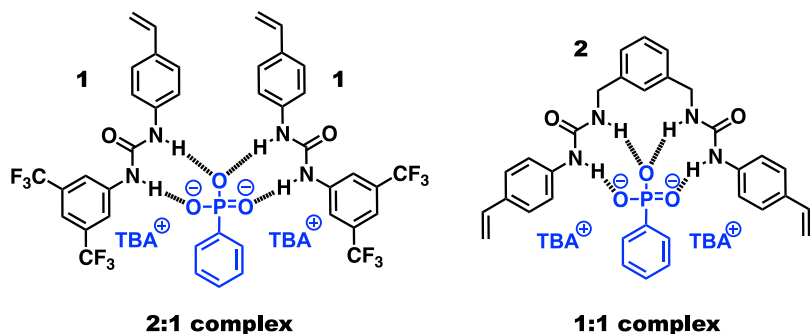

Considering oxyanion-oxourea complexation, the stability has been shown to increase in the order of increasing acceptor basicity, i.e., $\mathrm{PhSO}_{3}{ }^{-}<\mathrm{PhOP}(\mathrm{OH}) \mathrm{O}_{2}{ }^{-}<\mathrm{PhP}(\mathrm{OH}) \mathrm{O}_{2}{ }^{-} \leq$ $\mathrm{PhCOO}^{-}<\mathrm{PhPO}_{3}{ }^{2}-\leq \mathrm{PhOPO}_{3}{ }^{2-}{ }^{43}$ To verify this trend we decided to investigate $\mathbf{1}$ with respect to its complex stability with model anions in the form of TBA-salts of PPA, PPrA, BA, and PSA. Interaction strength and complex stoichiometries were investigated through ${ }^{1} \mathrm{H}$ NMR titration or isothermal titration calorimetry (ITC) (see the Supporting Information (SI)). Titrating 1 with PPA.TBA in DMSO- $\mathrm{d}_{6}$ and PPA.2PMP in THF- $\mathrm{d}_{8}$ resulted in strong downfield shifts of urea protons $\mathrm{Ha}$ and $\mathrm{Hb}$ and more moderate shifts of the aromatic protons Hc-f (Figure S1). The moderate downfield shift of $\mathrm{He}$ and upfield shift of $\mathrm{Hf}$ are in agreement with previous NMR titration study of 1,3-bis(4-nitrophenyl)urea with acetate. ${ }^{44}{ }^{1} \mathrm{H}$ NMR studies using Jobs method of continuous variation confirmed a preferred 1:1 stoichiometry. Complex stability constants were calculated using the induced downfield shifts of the urea protons of $\mathbf{1}$ (Figure S1). With respect to monoanions, 1 formed more stable complexes with benzoate anion BA $\left(K_{\mathrm{eq}}=8820 \mathrm{M}^{-1}\right)$ followed by PPA $\left(K_{\mathrm{eq}}=7005\right.$ $\left.\mathrm{M}^{-1}\right)$ and PPrA $\left(K_{\mathrm{eq}}=676 \mathrm{M}^{-1}\right)$, whereas the complex with the sulfonate PSA was too weak to be detected (Table S1). This agrees with the trend determined by Kelly et al. ${ }^{43}$ Comparing with monoanions, the dianions of PPA and PPrA interact more strongly with $1 .{ }^{28}$ The relative affinity of the two dianions is reflected in the downfield shifts of $\mathrm{Ha}$ and $\mathrm{Hb}$ (Figures 1 and 2) where PPrA (Figure 1c) display larger shifts than PPA (Figure 1b), again in line with the literature results.

To gain more insight we performed molecular dynamics (MD) simulations of the prepolymerization mixtures. MD simulations offer unique insights into the nature of the interactions between polymerization mixture components providing diagnostic/prognostic correlation to polymer performance. ${ }^{46,47}$ Compositions of simulated and evaluated systems and chemical structures are presented in Table 2 and Figure S15.

Full system all-atom simulations were performed using the same stoichiometries employed for polymer synthesis. The results overall confirmed the presence of stable interactions between the neutral, mono-, and di-valent anions of PPA and 1 (Tables 3 and S8-S10 and Figure S15) with the dianion of PPA (PP2) (PPrA not investigated using MD) displaying a

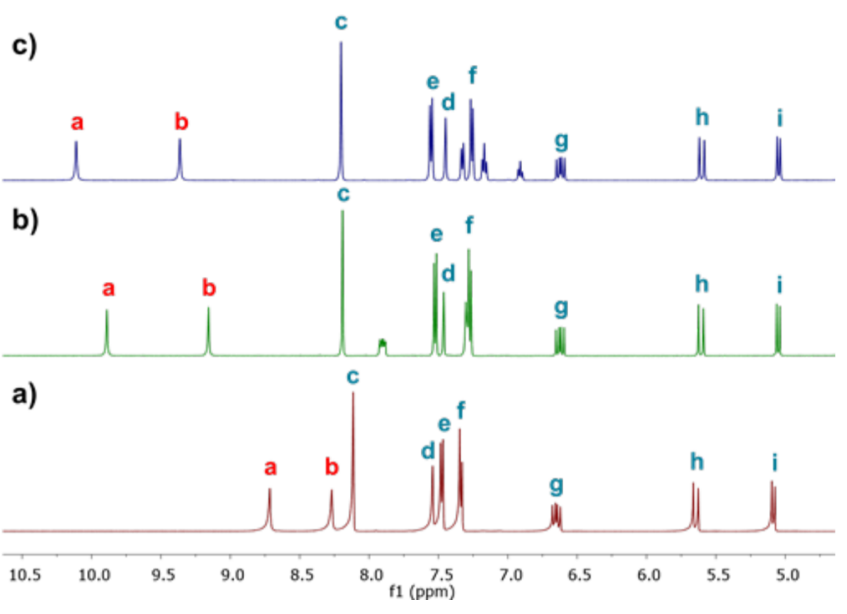

Figure 1. ${ }^{1} \mathrm{H}$ NMR spectra of (a) 1 and (b) 2:1 ratio of 1:PPA.2PMP and (c) 2:1 ratio of 1:PPrA.2PMP in THF- $\mathrm{d}_{8}$. [1] $=30 \mathrm{mM}$.<smiles>C=Cc1ccc(N(C)C(=O)N(C)c2cc(C(F)(F)F)cc(C(F)(F)F)c2)cc1F</smiles>

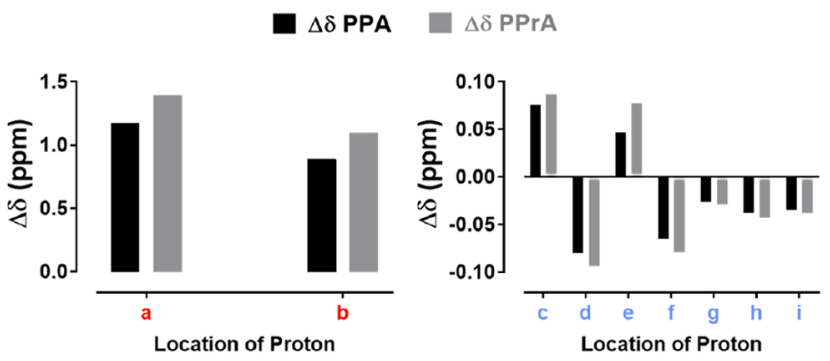

Figure 2. ${ }^{1} \mathrm{H}$ NMR chemical shift changes of urea host monomer 1 complexation with PPA.2PMP or PPrA.2PMP. $\Delta \delta=\delta$ (in the presence of anion) $-\delta$ (in the absence of anions), induced by addition of $1 / 2$ equiv of different anions to receptor 1 .

higher degree of H-bonding than the monoanion (PP1) or neutral PPA template.

However, the monoanionic PSA template (PS1) performs as well, even slightly better than PP2 considering complex formation with 1 (Tables S8-S10). A rank order of affinity for 1 was observed where anionic neutral PSA $<$ neutral PPA $<$ anionic PP1 < dianionic PP2 < PS1 (Tables 3 and S8-S10). This obviously disagrees with the NMR results where no interactions between PS1 and 1 could be detected. The systems differ though with respect to solvent polarity, the base, presence of cross-linker, and the concentration of all species which we believe can account for these contrasting results (vide infra). ${ }^{45-48}$

To gain further insight into the nature of the urea complexes between 1 and the two anions we performed 2D-NOESY NMR experiments and molecular modeling as reported by others. ${ }^{11}$ As shown in Figure 3a the free 1 shows strong crosspeaks with the residual water signal at ca. $2.9 \mathrm{ppm}$ indicating water protons close in space to the urea protons. In addition, weaker cross-peaks are observed between the two-urea protons $\mathrm{Ha}$ and $\mathrm{Hb}$ resulting from the Z,Z-urea conformer with the two protons juxtaposed (Figure $3 \mathrm{e}$ ). The addition of half an equivalent of PPA.2PMP (Figure $3 \mathrm{~b}$ ) and PPrA-2PMP (Figure 
Table 2. Composition of Systems Simulated and Evaluated ${ }^{a}$

\begin{tabular}{|c|c|c|c|c|c|c|c|c|}
\hline$c$ & $\mathrm{P} 1 \mathrm{~N}$ & $\mathrm{P} 1 \mathrm{C}$ & $\mathrm{P} 2 \mathrm{~N}$ & $\mathrm{P} 2 \mathrm{C}$ & P3N & P3C & $\mathrm{P} 4 \mathrm{~N}$ & P4C \\
\hline$T^{b}$ & PPA & PP1 & PPA & PP2 & PSA & PS1 & PSA & PS1 \\
\hline $\mathrm{PMP}^{b}$ & 20 & & 40 & & 20 & & 40 & 20 \\
\hline $\mathrm{PMPH}^{+b}$ & & 20 & & 40 & & 20 & & 20 \\
\hline 1 & 20 & 20 & 40 & 40 & 20 & 20 & 40 & 40 \\
\hline EGDMA $^{b}$ & 800 & 800 & 800 & 800 & 800 & 800 & 800 & 800 \\
\hline THF & 2760 & 2760 & 2760 & 2760 & 2760 & 2760 & 2760 & 2760 \\
\hline
\end{tabular}

${ }^{a}$ Numbers of virtual molecular models of each molecule included in performed simulations of systems. See Figure S15 for molecular representations and defined abbreviations. ${ }^{b} T=$ template $(20$ equiv $)$, PP1 $=$ PPA monoanion, PP2 = PPA dianion, PS1 = PSA monoanion, PMP $=$ 1,2,2,6,6-pentamethylpiperidine, EGDMA = ethylenglycoldimethacrylate. ${ }^{c} \mathrm{PXN} / \mathrm{C}$, Polymer system X, neutral (N) or charged (C).

Table 3. H-Bond Analysis Results ${ }^{a}$

\begin{tabular}{|c|c|c|c|c|c|c|c|}
\hline & & $T^{b}$ & PMP & $\mathrm{PMPH}^{+}$ & 1 & EGDMA & THF \\
\hline \multirow[t]{3}{*}{ P1C } & PP1 & 0.00 & & 0.00 & 0.11 & 0.00 & 0.00 \\
\hline & $\mathrm{PMPH}^{+}$ & 64.54 & & 0.00 & 0.00 & 0.00 & 0.01 \\
\hline & 1 & 24.26 & & 0.00 & 0.11 & 18.27 & 9.50 \\
\hline \multirow[t]{2}{*}{ P1N } & PPA & 77.27 & 0.00 & & 0.04 & 46.69 & 18.41 \\
\hline & 1 & 13.42 & 0.00 & & 0.10 & 25.93 & 12.96 \\
\hline \multirow[t]{2}{*}{$\mathrm{P} 2 \mathrm{C}$} & $\mathrm{PMPH}^{+}$ & 23.42 & & 0.00 & 0.00 & 0.00 & 0.00 \\
\hline & 1 & 74.37 & & 0.00 & 0.27 & 15.11 & 7.55 \\
\hline \multirow[t]{2}{*}{$\mathrm{P} 2 \mathrm{~N}$} & PPA & 38.96 & 0.00 & & 0.09 & 77.59 & 14.66 \\
\hline & 1 & 33.57 & 0.00 & & 0.50 & 48.62 & 24.68 \\
\hline \multirow[t]{2}{*}{ P3C } & $\mathrm{PMPH}^{+}$ & 75.69 & & 0.00 & 0.00 & 0.00 & 0.13 \\
\hline & 1 & 47.39 & & 0.00 & 0.05 & 11.84 & 6.02 \\
\hline \multirow[t]{2}{*}{ P3N } & PSA & 0.08 & 0.00 & & 0.02 & 2.80 & 2.00 \\
\hline & 1 & 1.06 & 0.00 & & 0.36 & 29.18 & 14.78 \\
\hline \multirow[t]{2}{*}{ P4C } & $\mathrm{PMPH}^{+}$ & 80.58 & 0.00 & 0.00 & 0.00 & 0.00 & 0.01 \\
\hline & 1 & 85.22 & 0.00 & 0.00 & 0.19 & 16.85 & 7.15 \\
\hline \multirow[t]{2}{*}{ P4N } & PSA & 0.08 & 0.00 & & 0.05 & 2.76 & 2.00 \\
\hline & 1 & 1.50 & 0.00 & & 0.39 & 30.18 & 15.69 \\
\hline
\end{tabular}

${ }^{a}$ Summarized average interactions, as percent of total simulation time, between all atom pairs of indicated molecular species. See Figure $S 15$ for molecular representations and defined abbreviations. All analyses involving templates were averaged against the number of templates ( 20 in each system). All interactions including the urea monomer 1 but not the template was averaged against the number of urea monomer molecules in each system (see Table 2). Cross-linker interactions with solvent and bases were averaged against the number of cross-linkers ( 800 in all systems) and, finally, base self-interaction and solvent interaction were averaged against the number of base molecules in each system (20 in P1, P3 N/C systems and $\mathrm{P} 4 \mathrm{C}, 40$ in $\mathrm{P} 2 \mathrm{~N} / \mathrm{C}$ and $\mathrm{P} 4 \mathrm{~N}$ systems). ${ }^{b}$ Interactions with the template in the analyzed system.

$3 c)$ to $\mathbf{1}$ gave rise to a stronger NOE between these protons and an interesting crosspeak between the more acidic $\mathrm{Ha}$ proton and the exchangeable $\mathrm{PMPH}^{+}$proton, visible as a broad signal at $3.5 \mathrm{ppm}$ (Figure S1e).

The former reflects stabilization of the Z,Z-conformer, whereas the latter a close contact between 1 and PMP, this providing an indirect support for the existence of the anticipated ternary complex between 1, PMP and the dianions (Scheme 4) This is in agreement with previous reports on urea- and squaramide-based sulfate receptors. ${ }^{12,49}$ Results from MD simulations also support the argument for higher order complexes observed in cameo images from the production run (Figures S16 and S17) and in the radial distribution function (RDF) analyses (Table 4).

As expected, the degree of complexation increases with the template charge, e.g., P2C ( $\mathrm{T}=\mathrm{PPA}$ dianion) display clusters involving any part of 6 molecules of 1 within $5 \AA$ from a template molecule, whereas only half of this number is seen in P1C. Generally, $\mathrm{PMPH}^{+}$was found in the simulations to be in close proximity to the templates and engaged in extensive $\mathrm{H}$ bonding with charged templates (Table 3 ). These results support the observed solubilization of the template PPA.2PMP in the presence of $\mathbf{1}$ in THF (Scheme 4). Whereas the ammonium phosphonate salt was poorly soluble in this solvent, the solution became completely clear after addition of 2 equiv of 1 . This provides unequivocal visual proof for the presence of prepolymerization complexes between 1 and PPA. 2PMP.

Polymer preparation and characterization. Imprinted and nonimprinted polymers were thereafter prepared and characterized (see SI and Tables S2-S4) using the urea host monomer 1 in a $2: 1$ and $1: 1$ stoichiometric ratio to the templates: PPA, PSA, or BA in their monoanionic or dianionic forms (Scheme 4). Nonimprinted polymers $\left(P_{N}\right)$ were prepared identically to the imprinted polymers though in the absence of template. Figure S2 shows the $25-36 \mu \mathrm{m}$ particle fraction obtained after crushing and sieving of the polymer monoliths and template removal by solvent extraction. These were subjected to physical characterization as follows: $\mathrm{C}, \mathrm{H}$, and $\mathrm{N}$ elemental analysis of imprinted and nonimprinted polymers after removal of template matched calculated values after correction for water uptake. This is reflected in the agreement between calculated and found N/C ratios (Table S3). Thermogravimetric analysis (TGA) of the polymers produced weight loss curves typical for highly cross-linked networks with onset above $200{ }^{\circ} \mathrm{C}$ (Figure S3) and complete weight loss obtained at $450{ }^{\circ} \mathrm{C}$. Meanwhile, the transmission FTIR spectra (Figure S4) showed all characteristic bands with 


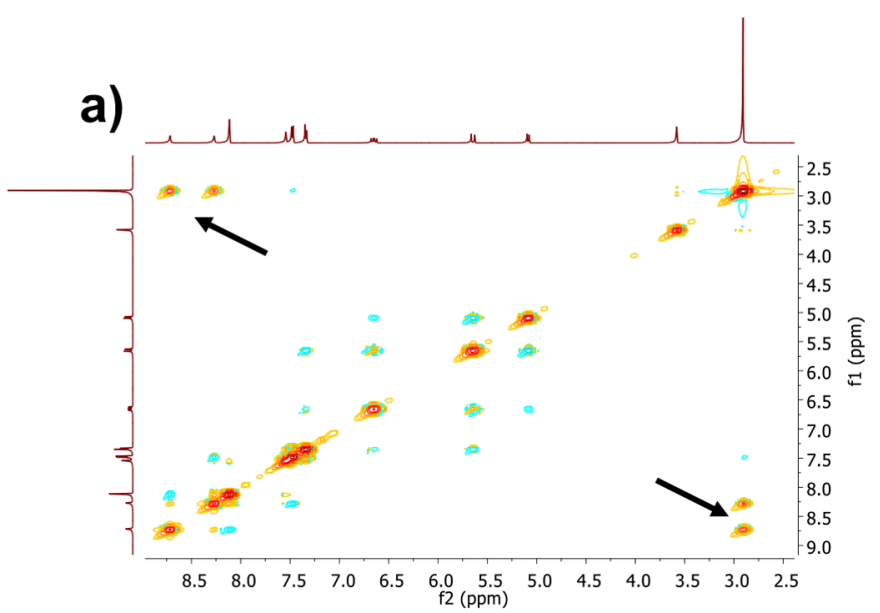

b)
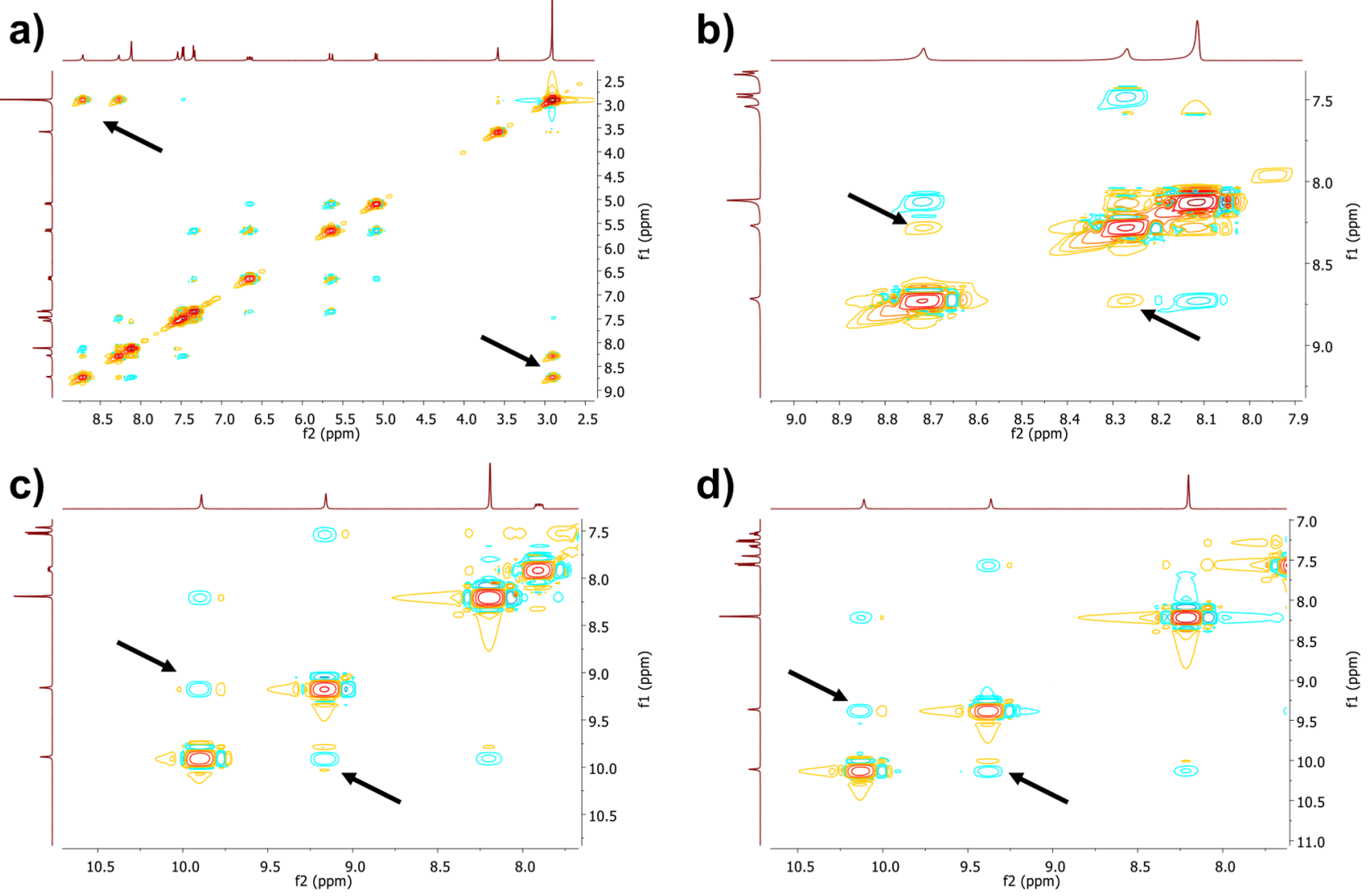

d)

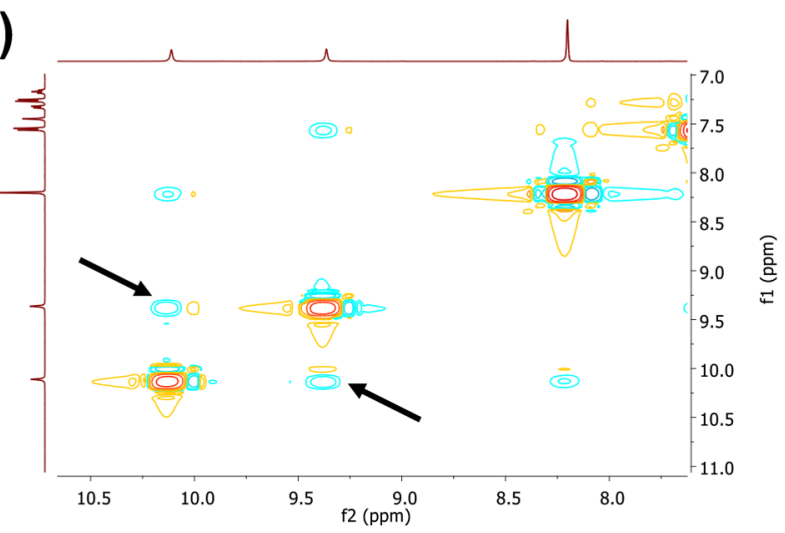

e)
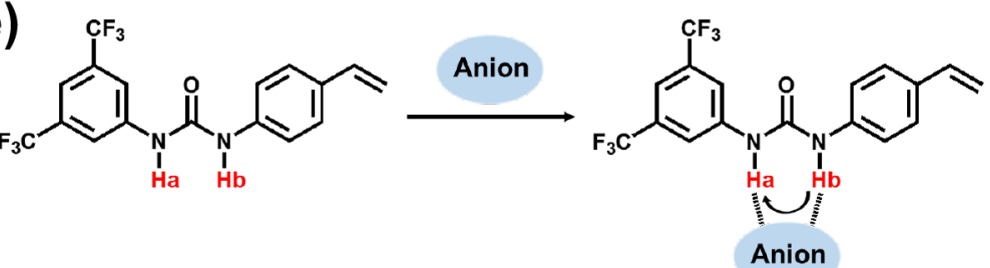

Figure 3. ${ }^{1} \mathrm{H}-{ }^{1} \mathrm{H}$ NMR NOESY spectra of 1: (a) and (b) (close-up), (c) 2:1 ratio of 1:PPA.2PMP and (d) 2:1 ratio of 1:PPrA-2PMP in THF- $d_{8}$ and (e) anion induced conformational stabilization detected by an increase ${ }^{1} \mathrm{H}-{ }^{1} \mathrm{H}$ NMR NOESY between $\mathrm{Ha}$ and $\mathrm{Hb}$. [1] $=30 \mathrm{mM}$. The arrows indicate the urea-water (a) and urea- $\mathrm{Ha}, \mathrm{Hb}$ cross peaks $(\mathrm{b}-\mathrm{d})$.

Scheme 4. Solubilization of the Bis-PMP-Salt of PPA by the Addition of 2 Equiv of Urea Host Monomer 1 in THF and Procedure for Imprinting

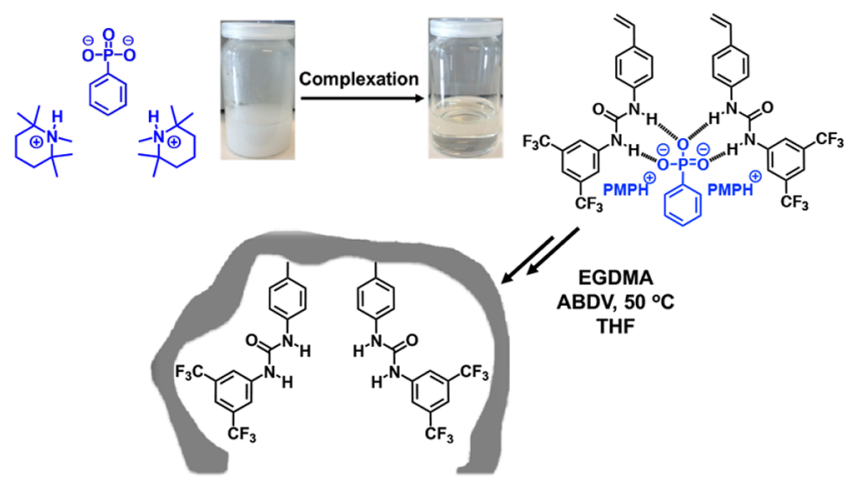

no apparent difference between imprinted and nonimprinted polymers all in all, indicating a stoichiometric monomer
Table 4. Numbers of Molecules within a $5.05 \AA$ Cutoff from Each Template ${ }^{a}$

$\begin{array}{lrccccc} & \text { EGDMA } & \text { PMPH }^{+} & \text {PMP } & \text { T } & \text { THF } & 1 \\ \text { T-P1C } & 8 & 13 & & 0 & 15 & 3 \\ \text { T-P1N } & 12 & & 0 & 5 & 17 & 1 \\ \text { T-P2C } & 5 & 33 & & 0 & 7 & 6 \\ \text { T-P2N } & 13 & & 0 & 2 & 17 & 3 \\ \text { T-P3C } & 8 & 14 & & 1 & 14 & 4 \\ \text { T-P3N } & 12 & & 0 & 0 & 21 & 1 \\ \text { T-P4C } & 8 & 11 & 0 & 0 & 14 & 6 \\ \text { T-P4N } & 12 & & 1 & 0 & 20 & 1\end{array}$

${ }^{a}$ Values presented are obtained through integration of $\mathrm{RDFs}$, assuming the template as the solute molecule with an average number of molecules within the cutoff for an average template.

incorporation and successful template removal from the imprinted polymers. 
This contrasted with the results from nitrogen sorption analysis and swelling tests, both reflecting the porous and structural properties of the polymers (Figure S5, Table S4). All polymers exhibited mesoporous morphology with surface areas exceeding $200 \mathrm{~m}^{2} \mathrm{~g}^{-1}$ and average pore diameters of roughly 4 $\mathrm{nm}$. However, in agreement with our previous report, ${ }^{28}$ the imprinted polymers showed a lower surface area and a higher swelling factor than the nonimprinted polymers. We tentatively attributed this template-induced difference in morphology to two effects of the divalent anion, (1) its action as a physical cross-linking agent and (2) its action as a good solvent for the growing chains leading to delayed phase separation and a more gel-like morphology. Below we will invoke a third alternative explanation to the observed differences based on the dianions ability to coordinate two monomer units of $\mathbf{1}$ in a geometry favoring cyclopolymerization (vide infra).

Template Binding Studies. To evaluate the anion recognition properties of the materials we first assessed their ability to rebind their corresponding templates under static conditions. The polymers were incubated in acetonitrile in presence or absence of base (PMP) with the anion templates (Figure 4) followed by quantification of unbound template by HPLC.

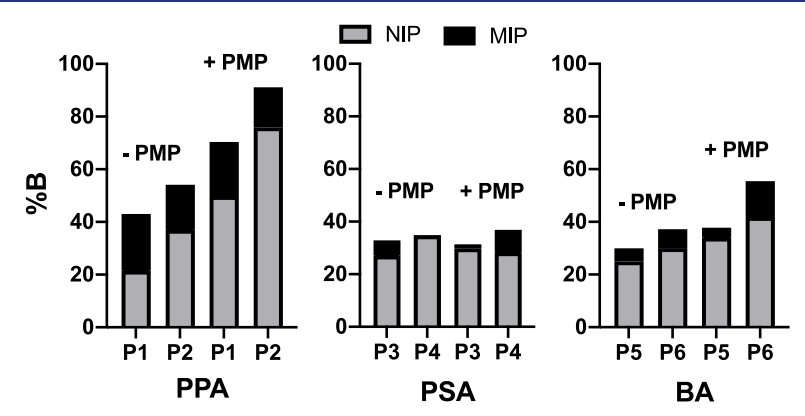

Figure 4. Absorbed amount in percent of PPA (a), PSA (b), and BA (c) by anion imprinted and nonimprinted polymers in the absence and presence of $0.1 \%$ PMP modifier.

Figure 4 shows the degree of template binding to the polymers in presence or absence of PMP. MIPs generally bound more of the templates than nonimprinted polymers (NIPs) with the largest uptake shown by the polymers prepared from a 2:1 monomer/template ratio and with a significant increase observed upon PMP initiated deprotonation. These results are all in line with the anticipated binding model and both observations correlate with the MD simulation results, whereby increasing the amount of functional monomer in the prepolymerization mixtures increases the extent of template H-bonding (Table 3). Furthermore, template complexation with PPA increases with the degree of deprotonation (neutral < monoanion $<$ dianion). Increasing the amount of PMP will increase the degree of template deprotonation, which increases the degree of interaction with 1. Ranking the polymers in order of decreasing uptake showed that only PPA, and to a lesser extent BA, led to polymers exhibiting these effects, whereas the PSA imprinted polymers lacked significant affinity for the template. This agrees with the weak basicity of the corresponding anions and weak interactions observed for this anion in aprotic solvents. The poor performance of the BA-MIPs P5 and P6 however, disagrees with the basicity trend. To understand the reason for this, the differencies in anion size and functionality should be considered. PPA monoanion is larger and features an additional $\mathrm{H}$-bond donor in $\mathrm{PhP}(\mathrm{OH}) \mathrm{O}_{2}{ }^{-}$which can interact with the polymer. This is lacking in $\mathrm{PhCO}_{2}{ }^{-}$. In view of the observed trends, we chose to characterize the PPA imprinted polymers in more detail.

Adsorption Isotherms and Binding Parameters. The binding-energy distribution of the polymers was obtained from single-component adsorption isotherms determined by a batch equilibrium binding experiment. ${ }^{50}$ The binding curves of PPA on $\mathrm{P} 1 / \mathrm{P}_{\mathrm{N}} 1$ and $\mathrm{P} 2 / \mathrm{P}_{\mathrm{N}} 2$ in acetonitrile buffered with $\mathrm{PMP}$ are seen in Figure $5 \mathrm{a}$ and $5 \mathrm{~b}$. Comparing different binding

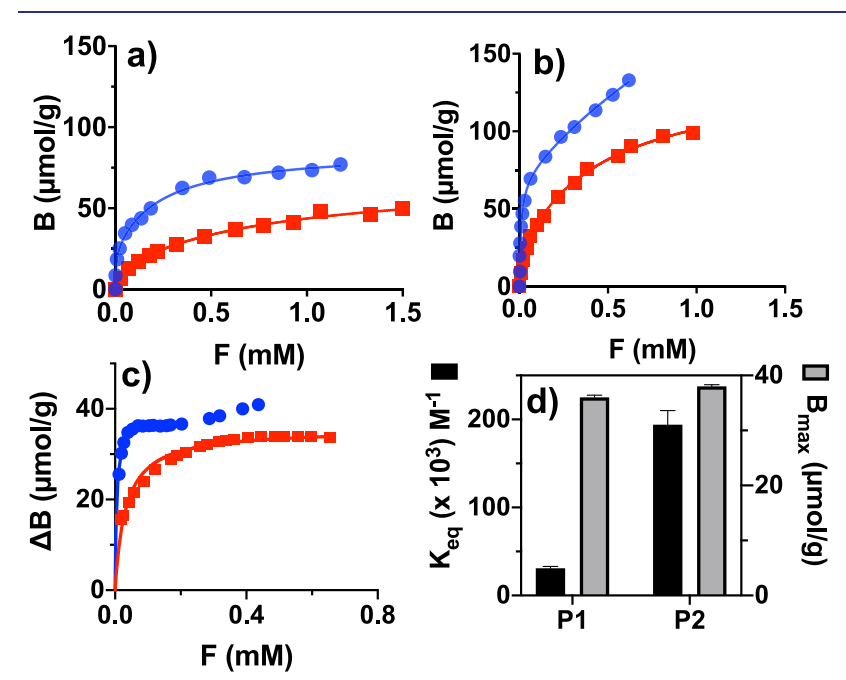

Figure 5. Equilibrium binding isotherms of PPA adsorbed to P1 (blue circles) and $\mathrm{P}_{\mathrm{N}} 1$ (red squares) (a) and $\mathrm{P} 2$ (blue circles) and $\mathrm{P}_{\mathrm{N}} 2$ (red squares) (b) in acetonitrile (0.1\% PMP). In (c) the binding to P1 (red squares) and P2 (blue circles) corrected for binding to the corresponding nonimprinted polymers is shown. The isotherms were fitted to a Langmuir binary-site ( $a, b)$ or monosite (c) models resulting in the binding parameters listed in Table 5. In c, the data points above $X=0.2$ have been excluded from the fitting of the data for P2. (d) shows the binding parameters obtained from Figure 5c.

equations (Figure S6) showed that the data were best fitted to the Langmuir binary site model. The associated binding parameters are given in Table 5. The curves exhibited saturation behavior with $\mathrm{P} 2 / \mathrm{P}_{\mathrm{N}} 2$ taking up approximately two times more PPA at a given free concentration. This is in line with the nominal capacity of the materials, which is two times higher for $\mathrm{P} 2 / \mathrm{P}_{\mathrm{N}} 2$ than $\mathrm{P} 1 / \mathrm{P}_{\mathrm{N}} 1$ and correlates with results derived from MD simulations. The NIPs displayed consistently less binding than the MIPs with the corresponding binding curves rapidly diverging in the low concentration interval of $0-0.5 \mathrm{mM}$. This appears clearly in the plots of the differential uptake in Figure 5c reflecting MIP binding corrected for binding to the NIP (assuming the latter to reflect the nonspecific binding contribution). Both of these curves fitted with a Langmuir monosite model resulted in nearly identical $B_{\max }$ values reflecting a similar imprinting efficiency of ca. $30 \%$ (given identical template concentration in the prepolymerization mixture) and with P2 showing a markedly higher affinity than P1 (Figure 5d). The latter is reflected in the higher equilibrium constant of P2 $\left(K_{\mathrm{eq}}=1.9 \times\right.$ $\left.10^{5} \mathrm{M}^{-1}\right)$ versus P1 $\left(K_{\mathrm{eq}}=3.1 \times 10^{4} \mathrm{M}^{-1}\right)$.

This difference can be attributed to the state of template complexation prior to polymerization and is supported by the results obtained from MD simulations. Again, both $\mathrm{H}$-bond 
Table 5. Equilibrium Constants $\left(K_{\mathrm{eq}}\right)$ and Binding Capacities $\left(B_{\max }\right)$ of PPA Imprinted Polymers ${ }^{a}$

$\begin{array}{lccccc}\text { polymer } & \text { site class } & K_{\text {eq }}\left(\times 10^{3} \mathrm{M}^{-1}\right) & B_{\max }(\mu \mathrm{mol} / \mathrm{g}) & R^{2} & \mathrm{IE}^{b}(\%) \\ \mathrm{P} 1 & \text { HI } & 265 \pm 107 & 23 \pm 3 & 0.99 & 18 \\ & \text { LO } & 4.4 \pm 0.8 & 63 \pm 2 & 0.99 & 50 \\ \mathrm{P}_{\mathrm{N}} 1 & \mathrm{HI} & 24 \pm 22 & 14 \pm 8 & 0.99 & \\ & \text { LO } & 1.1 \pm 0.6 & 56 \pm 5 & 0.99 & \\ \mathrm{P} 2 & \text { HI } & 110 \pm 52 & 70 \pm 14 & 0.97 & 56 \\ & \text { LO } & 0.4 \pm 1.2 & 326 \pm 804 & 0.97 & 260 \\ \mathrm{P}_{\mathrm{N}}{ }^{2} & \text { HI } & 53 \pm 30 & 24 \pm 8 & 0.99 & \\ & \text { LO } & 2 \pm 0.5 & 115 \pm 5 & 0.99 & \\ \mathrm{P}_{\text {corr }}{ }^{c} & & 31 \pm 2 & 36 \pm 0.4 & 0.96 & 29 \\ \mathrm{P} 2_{\text {corr }}{ }^{c} & & 194 \pm 16 & 38 \pm 0.3 & 0.96 & 31\end{array}$

${ }^{a}$ The binding parameters were obtained by fitting of the binding data in Figure 5 to a Langmuir monosite $\left(\mathrm{P} 1_{\text {corr }}, \mathrm{P} 2_{\text {corr }}\right)$ or binary site binding model. ${ }^{b}$ Imprinting efficiency IE $=100 \times B_{\max } / B_{\max } *$, where $B_{\max }{ }^{*}=125 \mu \mathrm{mol} / \mathrm{g}=$ nominal capacity assuming quantitative template removal and reoccupancy. ${ }^{c}$ Fitting parameters for isotherms corrected for nonspecific binding to nonimprinted polymer (e.g., $\Delta \mathrm{B}$ $\left.=\mathrm{B}_{\mathrm{P} 1}-\mathrm{B}_{\mathrm{PN} 1}\right)$.

analysis results (Table 3) and the RDF-analysis (Table 4) indicate a higher degree of complexation of $\mathbf{1}$ with the template when increasing the amount of monomer.

On the basis of mass balance equations and assuming the solution complexation constants in Table S1, we predict that PPA is present in the form of a 1:1 complex, whereas for P2, ternary complexes are dominating. Turning to the RDF-results (Table 4), the calculated number of molecules within the given cutoff varies with the cutoff and order of the selected solvent/ solute pairs. However, in the neutrally templated PPA system $\left(\mathrm{P}_{\mathrm{N}} 1\right)$ there is one molecule of 1 within $5 \AA$ of any average template. This number increases to three when either increasing the amount of $\mathbf{1}$ or deprotonating the template PPA to monoanionic PPA. This offers support for the suggested complexation model that indicates the formation of ternary complexes. Increasing the amount of base further leads to dianionic PPA for which RDF results (Table 4) show six molecules of $\mathbf{1}$ in close proximity to any template. The results obtained moving from 1:1, through $3: 1$ to $6: 1$ stoichiometries of $\mathbf{1}$ and template complexes, in association with the base driven increase in degree of deprotonation, add support for the formation of ternary complexes.

Assuming that the structures of the prepolymerization complexes are carried into the polymer scaffold, the 1:2 complex will result in a cleft-like receptor featuring four $\mathrm{H}$ bond donors, whereas the 1:1 complex will yield a site with a 2fold H-bond donor. Accounting for the entropic gain, the resulting binding constant can exceed that of the $1: 1$ site by $2-$ 3 orders of magnitude, which is clearly not the case here. Plausible explanations for this disagreement will be discussed below.

Switchable Oxyanion Selectivity. The crushed polymer monoliths of $\mathrm{P} 1 / \mathrm{P}_{\mathrm{N}} 1$ and $\mathrm{P} 2 / \mathrm{P}_{\mathrm{N}} 2$ were sieved and packed in columns for chromatographic characterization of their retentive properties for the model oxoacids (Scheme 1). The acids were injected in an acetonitrile rich mobile phase as such or buffered with either triethylamine (TEA) or trifluoroacetic acid (TFA). Basic conditions will promote deprotonation leaving the oxyanions to interact with the MIP via $\mathrm{H}$ bonding. ${ }^{28}$ The decisive role of this factor became obvious in the context of the MD simulations of the imprinting process.
Hence, increasing the extent of deprotonation of PPA strongly influences template complexation with both 1 and $\mathrm{PMPH}^{+}$.

The MIP exhibited strong affinity for its template (PPA) in this mobile phase (Figures 6 and Figures S7) with ca. $75 \%$ of

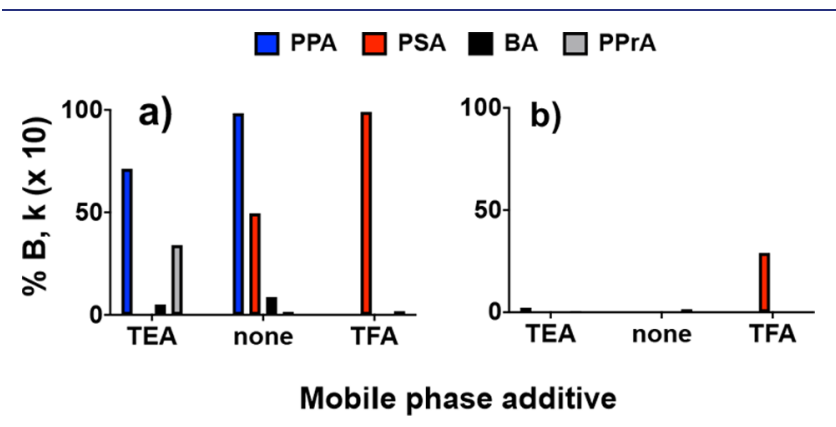

Figure 6. Percent bound (TEA, none) and retention factor $(k \times 10)$ (TFA) for PPA, PSA, BA, and PPrA on columns packed with P2 (a) and $\mathrm{P}_{\mathrm{N}} 2$ (b) using acetonitrile with different modifiers as mobile phases as follows: TEA: Acetonitrile/Water 90:10 (0.1\% TEA); TFA: Acetonitrile/Water 95:5 (0.1\% TFA); and none: 100\% Acetonitrile.

injected analyte remaining stuck on the column. Meanwhile, with the exception of P PrA, none of the other acids were retained whereas $\mathrm{P}_{\mathrm{N}} 2$ exhibited no affinity for any of the analytes. This contrasts with the retention results in the TFAbuffered mobile phase. Here we note a complete switch of anion preference with PSA being the only retained analyte. In absence of modifier both PPA and PSA are retained by P1 and $\mathrm{P} 2$ with no retention observed by nonimprinted $\mathrm{P}_{\mathrm{N}} 1$ and $\mathrm{P}_{\mathrm{N}} 2$.

A detailed look at the ionization states of the acids may offer clues to the origin of the turn on/off effect. Table S5 lists the $\mathrm{p} K_{\mathrm{a}}$ values and anticipated charges in the presence of the two modifiers of the acids in the study. In presence of base, PPA and $P P r A$ carry a net charge of -2 , whereas the monovalent acids are negatively charged -1 . In this state both PPA and PPrA can bind to the P2 site while benefiting from 4 complementary H-bond donors. The PPA dianion is the most strongly retained anion agreeing with the fact that this anion was used as template and hence fits best into the binding sites. The weak retention of the monovalent anion of PSA we ascribe to its weak basicity and its hydrophilicity, whereas planar BA lacks steric complementarity with the PPA templated site. In presence of TFA, however, $\left(\mathrm{p} K_{\mathrm{a}}=0.5\right), \operatorname{PPrA}\left(\mathrm{p} K_{\mathrm{a}}=0.9\right)$, and PPA $\left(\mathrm{p} K_{\mathrm{a}}=1.8\right)$ with $\mathrm{p} K_{\mathrm{a}}$ values in vicinity are partially or fully protonated weakening their interactions with the ureas of the stationary phase. PSA $\left(\mathrm{p} K_{\mathrm{a}}=-2.8\right)$ should be fully ionized in water but less so in $95 \%$ acetonitrile in the presence of TFA. As a consequence, PSA is less hydrated under these conditions and can more easily partition into the stationary phase. With only one of the three oxygen acceptors blocked by protonation PSA, as a crude mimic of the PPA dianion, is effectively recognized by the urea binding site.

Some insight is provided by the MD simulations. Regarding template rebinding in absence of modifier, it is clear from the $\mathrm{H}$-bond analysis results (Table 3 ) that with respect to neutral templates, 1 will interact more strongly with PPA than with PSA. This agrees with the observed retention order in pure acetonitrile (Figure 6a). These experimental results are based on investigations of polymer system $\mathrm{P} 2$, prepared using higher levels of 1 and PMP (Table 2, Figure S15). Interestingly, the $\mathrm{H}$-bond analysis results (Table 3 ) revealed that increasing the amount of $\mathbf{1}$ promotes template interaction while barely 
affecting involvement of $\mathrm{PMPH}^{+}$. Further, increasing the degree of deprotonation of template reduces templatetemplate interactions, which is reasonable given the increased charge repulsion. Strong support for the formation of higher order complexes is offered by the RDF analysis. The degree of aggregation is noticeable when inspecting the simulated systems visually (Figures 7, S16, and S17). There is a markedly

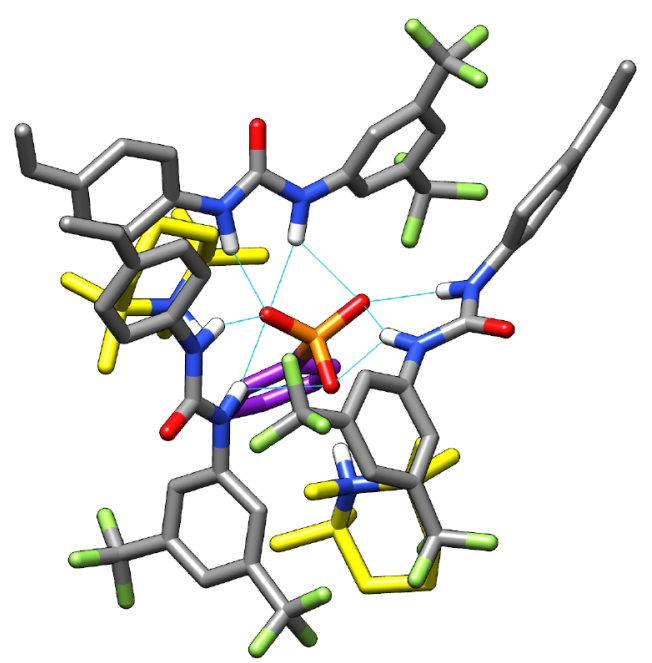

Figure 7. Example of an observed ternary complex in the P2C system, here involving three molecules of 1 (gray) engaged in H-bonding interactions with the template (PP2) (purple/magenta) and two non$\mathrm{H}$-bonding base molecules $\left(\mathrm{PMPH}^{+}\right)$(yellow). H-bonds are indicated with dashed lines.

higher presence of $\mathrm{PMPH}^{+}$(2-fold) in the vicinity of PPA in the P2C system (Table 4) than in all the other systems. This supports the presence of ternary complexes and their possible influence on polymer structure and morphology (vide infra). ${ }^{50}$

Binding of Inorganic Phosphate and Sulfate in Water. Given the strong and switchable ion binding shown by the MIP in water poor media, our next goal was to investigate whether the polymers would cross-react with inorganic anions in buffer. Several synthetic receptors have been developed for this purpose to address various water processing or sensing applications, ${ }^{6}$ but so far only few receptors have shown effective anion recognition in water and even more rare are those functioning in high ionic strength media. ${ }^{1,51}$ A key problem is that both phosphate and sulfate are strongly hydrated in water (Table 1) which has a destabilizing effect on the interactions with the imprinted site.

To increase particle wettability, we prepared a new set of polymers as $\mathrm{P} 2 / \mathrm{P}_{\mathrm{N}} 2$ but using pentaerythritoltriacrylate (PETA) as a hydrophilic crosslinker. Ion binding was measured by conductometry in buffer $\mathrm{pH}=9.0$ where both anions carry a net 2 -fold negative charge (Figure 8 ). To our surprise, clear imprinting effects were observed with P7 exhibiting a consistently higher uptake of both phosphate and sulfate compared to nonimprinted $\mathrm{P}_{\mathrm{N}} 7$. In agreement with the Hofmeister series, describing the salt effect on protein solubility, phosphate is the most strongly bound ion followed by PPA, sulfate and PSA, the trend being weaker on $\mathrm{P}_{\mathrm{N}} 7$ compared to P7 (Table 6). The effect of imprinting appears clearly in the plots of the differential uptake in Figure $8 \mathrm{c}$ reflecting MIP binding corrected for binding to the NIP (assuming the latter to reflect the nonspecific binding contribution). Fitting these data with the Langmuir monosite
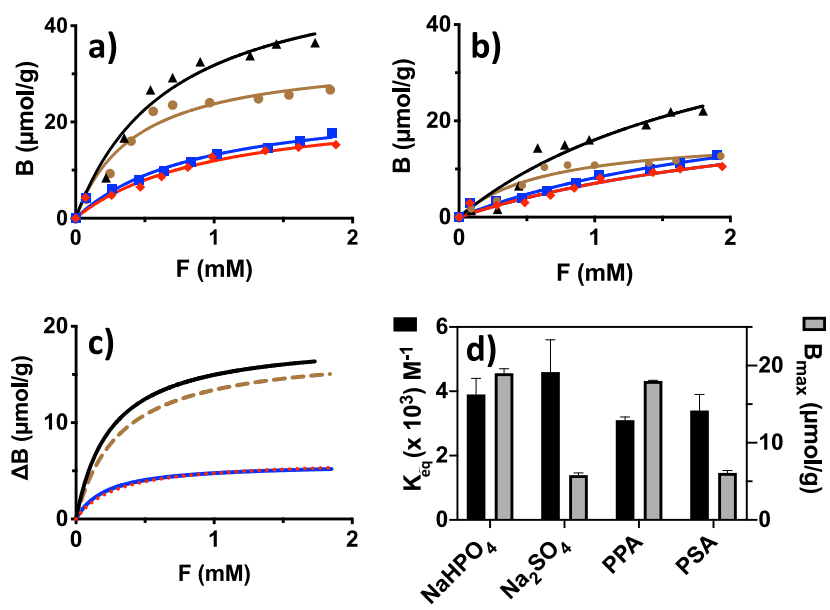

Figure 8. Equilibrium binding isotherms of $\mathrm{Na}_{2} \mathrm{HPO}_{4}$ (black curve, triangles), PPA (brown curve, circles), PSA (red curve, diamonds), and $\mathrm{Na}_{2} \mathrm{SO}_{4}$ (blue curve, squares) on polymer $\mathrm{P} 7(\mathrm{a})$ and $\mathrm{P}_{\mathrm{N}} 7$ (b) in $0.1 \mathrm{M}$ sodium bicarbonate buffer $\mathrm{pH}=9.0$ (c) Binding isotherms of P7 corrected for binding to the nonimprinted polymer $\mathrm{P}_{\mathrm{N}} 7$. (d) Equilibrium constants $\left(K_{\text {eq, }}\right.$ black bars $)$ and binding capacities $\left(B_{\max }\right.$ gray bars) for the indicated anions interacting with $\mathrm{P} 7$ in buffer $\mathrm{pH}$ 9.0 The binding parameters were obtained by fitting of the corrected binding data in (c) to a Langmuir monosite binding model.

Table 6. Equilibrium Constants $\left(K_{\mathrm{eq}}\right)$ and Binding Capacities $\left(B_{\max }\right)$ of PPA Imprinted Polymers ${ }^{a}$

$\begin{array}{clccc}\text { polymer } & \text { anion } & K_{\text {eq }}\left(\times 10^{3} \mathrm{M}^{-1}\right) & B_{\max }(\mu \mathrm{mol} / \mathrm{g}) & R^{2} \\ \mathrm{P7} & \mathrm{NaHPO}_{4} & 1.5 \pm 0.3 & 53 \pm 5 & 0.973 \\ & \mathrm{Na}_{2} \mathrm{SO}_{4} & 1.1 \pm 0.2 & 25 \pm 3 & 0.976 \\ & \mathrm{PPA} & 2.2 \pm 0.6 & 34 \pm 3 & 0.966 \\ & \mathrm{PSA} & 1.0 \pm 0.3 & 24 \pm 3 & 0.959 \\ \mathrm{P}_{\mathrm{N}} 7 & \mathrm{NaHPO}_{4} & 0.5 \pm 0.2 & 51 \pm 18 & 0.940 \\ & \mathrm{Na}_{2} \mathrm{SO}_{4} & 0.4 \pm 0.2 & 30 \pm 8 & 0.970 \\ & \mathrm{PPA} & 1.5 \pm 0.5 & 18 \pm 2 & 0.950 \\ & \mathrm{PSA}_{\mathrm{P}_{\text {corr }}} & 0.3 \pm 0.2 & 27 \pm 11 & 0.940 \\ & \mathrm{NaHPO}_{4} & 3.9 \pm 0.5 & 19 \pm 0.6 & 0.990 \\ & \mathrm{Na}_{2} \mathrm{SO}_{4} & 4.6 \pm 1.0 & 5.8 \pm 0.3 & 0.973 \\ & \mathrm{PPA} & 3.1 \pm 0.1 & 18 \pm 0.1 & 0.999 \\ & \mathrm{PSA} & 3.4 \pm 0.5 & 6.1 \pm 0.3 & 0.990\end{array}$

${ }^{a}$ The binding parameters were obtained by fitting of the binding data in Figure 8 to a Langmuir monosite binding model.

model resulted in the data shown in Figure 8d. Interestingly, in spite of the higher uptake of phosphate, sulfate binds with a slightly higher equilibrium constant $\left(K_{\mathrm{eq}}=4.6 \times 10^{3} \mathrm{M}^{-1}\right)$ than phosphate $\left(K_{\mathrm{eq}}=3.9 \times 10^{3} \mathrm{M}^{-1}\right)$. These values exceed the anion affinity of most reported neutral receptors with respect to anion binding in buffered media. ${ }^{4,5}$ To investigate a possible $\mathrm{pH}$ dependent anion preference, we also measured ion binding at lower $\mathrm{pH}$-values (Figure S8). Binding of both PPA and PSA decrease with decreasing $\mathrm{pH}$. Although an overturned binding preference could not be observed, the increase in the $B_{\mathrm{PSA}} / B_{\mathrm{PPA}}$ ratio shows that the preference for PPA decreases.

Investigation of Imprinting Mechanism. Having proven the binding performance of the anion imprinted receptors, further refinements require a fundamental understanding of the imprinting mechanism and the structural nature of the imprinted sites. An overlooked issue in molecular imprinting concerns the effect of template on the early stages of polymerization. $^{52-55}$ Is the template capable of inducing a 


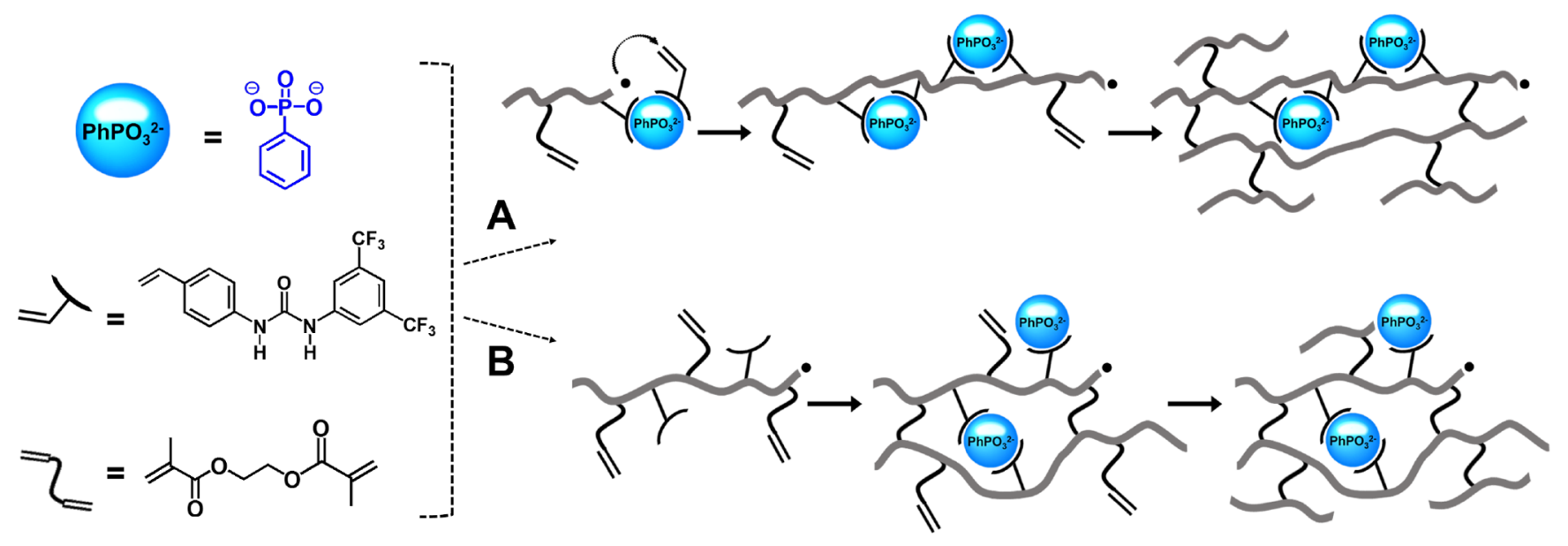

Figure 9. Alternative routes to the buildup of recognitive sites in network polymers. (A) Strong monomer-template interactions lead to template induced host monomer diads in the main chain that are subsequently stabilized by cross-linking. (B) Weak monomer-template interactions lead to sites formed by multidentade interactions involving preformed polymer chains. Counterions have been omitted for clarity.

preferred sequence or stereoregularity in the polymer main chain that may in turn influence its molecular recognition properties?

We raised this question in view of the ternary monomertemplate complexes anticipated to be present during polymerization, the presence of which finds strong support in results from the MD simulations (Tables 3 and 4 and Figures 7, S16, and S17). Such an arrangement may place the reactive double bonds of two monomers in close vicinity (see the left two molecules of $\mathbf{1}$ in Figure 7). One consequence of this arrangement may be a template induced incorporation of two urea groups juxtaposed in the same chain (Figure 9, route A) akin to the established template polymerization mechanism. ${ }^{55-58}$ The role of the template is here to bring two or more polymerizable groups close in space to achieve rate enhancement combined with stereo- and sequence- controlled monomer incorporation. The template can be covalently or noncovalently attached to the monomers and is cleaved off after polymerization to free up pendent functional groups. ${ }^{56}$ This results in high molecular weight copolymers with controlled tacticity and regularity.

To investigate whether monomer reactivity in our system is template controlled or the monomers are randomly incorporated, we used differential scanning calorimetry (DSC), NMR, and MALDI-TOF mass spectrometry to study the initial stages of polymerization. Cross-linked polymers P1 and P2 were compared with linear copolymers of $\mathbf{1}$ and methyl methacrylate (MMA). All polymers were prepared in absence or presence of template, the latter in the form of mono- or bis-TBA salts of PPA. First, we studied the curing process by DSC monitoring the heat generation upon double bond conversion. The onset and peak maxima temperatures of the curing exotherm were registered (Figures 10, S9, and S10), and the double bond conversion was estimated from the total heat generated per unsaturation divided by the literature value for the MMA double bond enthalpy $\left(\Delta H_{0}=13.1 \mathrm{kcal} / \mathrm{mol}\right)$ (Table S6). All copolymer curing systems experienced a lowering of the peak maxima temperatures upon added template, the effect being more pronounced for PPA.2TBA than for PPA.TBA (Figure 10a). This contrasted with the effect of template addition on the curing of MMA alone (Figure S10), where a slight increase in the onset temperature as well as a significantly lower
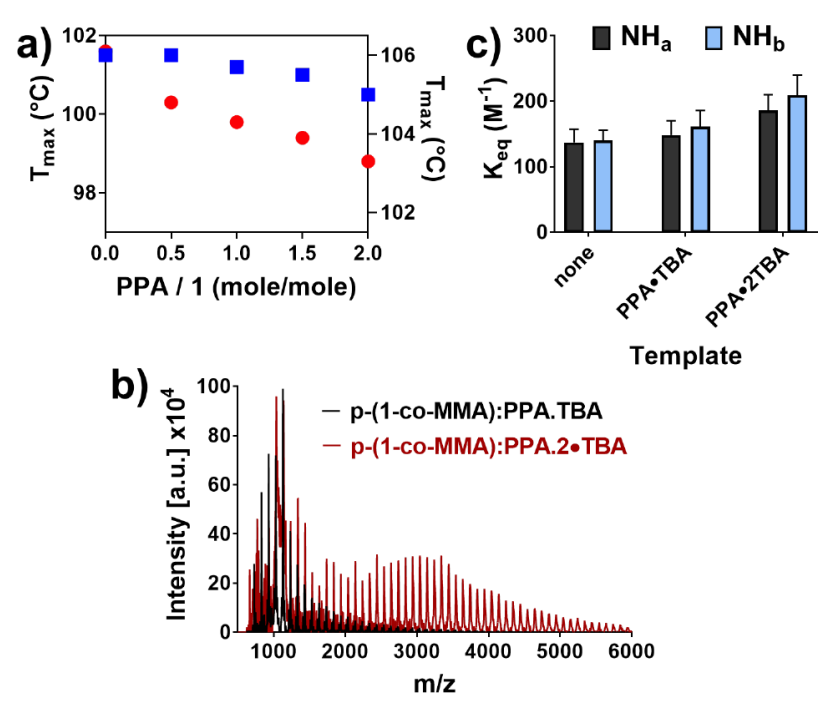

Figure 10. (a) Exotherm peak maxima temperatures upon curing of a mixture of 1 and MMA (1/MMA: $1 / 5 \mathrm{~mol} / \mathrm{mol})$ in the presence of PPA.2TBA (red circles) and PPA.TBA (blue squares). (b) MALDITOF-MS spectra of $\mathrm{p}-1$-co-MMA prepared in the presence of PPA. TBA (black spectrum) and PPA-2TBA (red spectrum). (c) Equilibrium constants of PPA.2TBA binding to imprinted and nonimprinted $\mathrm{p}$-(1-co-MMA). Data obtained from the binding curves in Figure S13 with fitting parameters listed in Table S7.

conversion was observed. This indicates that PPA acts as an inhibitor in absence of the host monomer. Overall, the template had no significant effect on the monomer conversion, which was $40-50 \%$ in all cases. We cautiously interpret these results as being due to a template assisted monomer incorporation with PPA.2TBA prearranging two molecules of 1 leading to a catalyzed propagation. The molecular weight distribution of $\mathrm{p}$-(1-co-MMA) determined by MALDI-TOFMS supports this explanation (Figures 10b and S11). This technique provides detailed information on the molar mass distribution, end groups, and repeat units of linear polymers and in the tandem mode, confirmation of their structural identity. $^{59}$

The polymers were isolated from the crude reaction mixtures by precipitation in methanol and deposited together 
Table 7. Properties of Linear Copolymers Prepared in the Presence of the Templates Indicated

\begin{tabular}{|c|c|c|c|c|c|c|}
\hline polymer & template & $\Delta T_{\max }{ }^{a}\left({ }^{\circ} \mathrm{C}\right)$ & $M_{\mathrm{w}}^{b}(\mathrm{~g} / \mathrm{mol})$ & $M_{\mathrm{n}}^{b}(\mathrm{~g} / \mathrm{mol})$ & $\mathrm{PDI}^{b}$ & $\mathrm{MMA} / 1^{c}$ \\
\hline p-MMA & PPA.2TBA & 0 & 1114 & 1025 & 1.09 & $\mathrm{n} / \mathrm{a}$ \\
\hline $\mathrm{p}-(1-c o-\mathrm{MMA})$ & none & $\mathrm{n} / \mathrm{a}$ & 1493 & 1174 & 1.27 & 1.74 \\
\hline $\mathrm{p}-(1-c o-\mathrm{MMA})$ & PPA.TBA & -1.0 & 1642 & 1319 & 1.24 & 2.36 \\
\hline $\mathrm{p}-(1-c o-\mathrm{MMA})$ & PPA.2TBA & -2.8 & 2700 & 1926 & 1.40 & 1.57 \\
\hline
\end{tabular}

${ }^{a}$ Change in exotherm peak maxima calculated from the data in Figures S9, S10, and 10a. ${ }^{b}$ Number $\left(M_{\mathrm{n}}\right)$ and weight $\left(M_{\mathrm{w}}\right)$ average molecular weights and polydispersity index (PDI) calculated as described in the $\mathrm{SI} .{ }^{c} \mathrm{Calculated}$ from the integrals of the signals corresponding to the $-\mathrm{OCH}_{3}$ protons of MMA $(\delta=3.6 \mathrm{ppm})$ and the aromatic protons Hc of $1(\delta=8.2 \mathrm{ppm})$.

with the MALDI matrix on the target plate followed by recording of the spectra. As seen in Figures $10 \mathrm{~b}$ and $S 11$ the oligomer distributions were found in the ranges $\mathrm{m} / \mathrm{z} 100-$ 1500 p-MMA; 500-4000 p-(1-co-MMA); 700-5000 p-(1-coMMA) (template: PPA-TBA); 800-7000 p-(1-co-MMA) (template: PPA-2TBA), with the signal mass separations corresponding to the expected repeat units i.e. $100.1 \mathrm{~g} / \mathrm{mol}$. The corresponding number $\left(M_{\mathrm{n}}\right)$ and weight $\left(M_{\mathrm{w}}\right)$ average molecular weights and polydispersity index (PDI) are listed in Table 7.

From these results we conclude that polymerization in the presence of the doubly charged template leads to a pronounced increase in the average molecular weight of the oligomers, and a significant reduction in polydispersity, all in agreement with the anticipated mechanism.

Finally, we analyzed all polymers by ${ }^{1} \mathrm{H}$ NMR spectroscopy. This technique has a broad information value in polymer chemistry. ${ }^{60}$ From integral ratios of incorporated monomers, the copolymer composition can be estimated, and the technique can be used to estimate the number-average molecular weight, ${ }^{56,61}$ and polymer stereo- and sequenceregularity. ${ }^{55}$ Of particular relevance in our case is whether the signals from pendent urea groups are visible and if yes, whether their affinity vis-à-vis the template can be determined.

Figure $\mathrm{S} 12 \mathrm{a}$ shows a representative solution spectrum (DMSO- $\left.d_{6}\right)$ of $\mathrm{p}$-(1-co-MMA) prepared in absence of template. We gratefully noted that protons characteristic for both monomers were clearly visible, i.e., the urea protons $\mathrm{Ha}$ and $\mathrm{Hb}$ and the aromatic protons $\mathrm{Hc}$ of $\mathbf{1}$ and the $-\mathrm{OCH}_{3}$ protons of MMA. The integrals of the $\mathrm{Hc}$ and $-\mathrm{OCH}_{3}$ signals were used to estimate the stoichiometry of incorporated monomers. This is expressed as the ratio MMA/1 and the values are listed in Table 7 . For all polymers the ratios are lower than $5 / 1$ indicating an enhanced incorporation of monomer $\mathbf{1}$ in the chains. More interesting, however, is the low ratio observed for the template induced polymers, most notably for the polymer prepared in the presence of the doubly charged template. This agrees with the anticipated catalytic action of PPA.2TBA enhancing the reactivity of 1 . We thereafter monitored the complexation induced shifts of the urea protons upon addition of PPA.2TBA. As seen in Figure $\mathrm{S} 12$, titration was accompanied by pronounced downfield shifts and signal broadening which confirm the expected template-polymer interactions. The CIS plots for all polymers are seen in Figure S13 with the binding parameters listed in Table S7. The increase of the average equilibrium constants from $K_{\mathrm{eq}}=139 \mathrm{M}^{-1}$ for the nontemplated polymer to $K_{\mathrm{eq}}=$ $198 \mathrm{M}^{-1}$ for the templated polymer we ascribe to an enhanced number of main chain 1-1 diads, configured to bind the template via multiple $\mathrm{H}$-bonds.

We therefore conclude that a template memory can be induced by control of the monomer sequence in the polymer main chain alone. So, what is the role of the cross-linking agent? Judging from the equilibrium constants for adsorption, the affinity of the cross-linked P2 for PPA $\left(K_{\text {eq }}=1.9 \times 10^{5}\right.$ $\mathrm{M}^{-1}$ ) exceeds by far that of the linear polymer. The contribution of cross-linking to the polymer affinity for the template is hence obvious. The importance of the cross-linking monomer is further highlighted in the results obtained from MD simulations. Looking at the neutral templated systems (PXN), cross-linker and $\mathbf{1}$ form H-bonds between 30 and 50\% of the total simulation time (Table 3). Even in the PPA templated systems, extensive $\mathrm{H}$-bonding between the template and the cross-linking monomer is observed, $60-80 \%$. There is a high presence of cross-linker around templates and competition for access to functional groups on templates. The interactions are also stable, often more so than interactions between template and 1 or $\mathrm{PMP} / \mathrm{PMPH}^{+} . \mathrm{H}$ bond interactions with template are lower in PSA systems than in PPA systems, even if the presence of cross-linker is similar. As observed in several other systems, ${ }^{445-48}$ the presence of cross-linker in close vicinity to the template is observed in prepolymerization mixtures and is observed to influence template-polymer rebinding.

\section{FINAL DISCUSSION}

Charge neutral receptors interacting with ligands via $\mathrm{H}$ bonding have for long been associated with poor compatibility with aqueous media. The presence of water and other protic solvents effectively disrupts the HG interactions in these systems. ${ }^{1}$ Some exceptions to this rule have recently been reported, although neutral receptors displaying affinity for phosphate and sulfate in pure water or buffer are still rare. Inspiration from naturally occurring receptors can be used to move forward. These display high affinity and selectivity in physiological conditions by shielding the anion from the surrounding solvent molecules and thereby freeing it to interact by $\mathrm{H}$-bonding in a nest like site. ${ }^{1,5}$ To mimic this principle, we have designed oxyanion imprinted polymers incorporating charge neutral urea groups in a hydrophobic scaffold. The polymers exhibit an unprecedented switchable anion binding behavior as well as strong ion affinity in buffered media comprising both phosphate and the strongly hydrated sulfate anion. This performance has a practical relevance in view of the broad need for robust anion binders. As we previously showed, this behavior may be exploited in bioseparations for fractionation of phosphorylated and sulfated peptides or saccharides. ${ }^{29}$ Another classical problem concerns sulfate separation from nitrate-rich radioactive mixtures which has been a long-term goal in nuclear waste remediation. ${ }^{6}$ Several synthetic receptors have been developed for this purpose but so far only few receptors offer effective anion recognition in water and even more rare are those functioning in high ionic strength media. Through further improvements of 
the imprinted receptors, such as incorporation of dual receptors ${ }^{62,63}$ or other scaffolds, we hope to sufficiently boost affinity and selectivity for the MIPs to offer a viable alternative host for these purposes.

We also provide detailed molecular level insight into the anion recognitive sites. Comparing stoichiometric imprinting based on $1: 1$ or $1: 2$ phosphate anion-urea monomer ratios shows the superiority of the ternary complex imprinting to generate high fidelity binding sites. In spite of the stoichiometric complexation as proven by ${ }^{1} \mathrm{H}$ NMR $2 \mathrm{D}$ NOESY and CIS plots, the imprinting efficiency did not exceed $30 \%$ when counting the high affinity sites. This is likely related to the amorphous nature of this class of MIPs, ${ }^{64}$ supported by the heterogeneity of observed complexes in these mixtures (Figures S16 and S17). MIPs prepared by free radical polymerization belong to the thermoset class of materials characterized by extensive and irreversible cross-linking and insoluble end products. The heterogeneity of these materials ranges from the molecular level to the micro scale which precludes molecular level insights into the structural and dynamic features of the binding sites. This stands in contrast to the range of available tools for characterizing biomacromolecules. Nevertheless, reports focusing on well characterized monomer template systems employing advanced techniques such as solid state NMR with isotopically enriched templates, ${ }^{65-68}$ infrared $^{69,70}$ or fluorescence spectroscopy $^{42,71,72}$ have increased our knowledge in this regard. As discussed above, the propagation rate versus the on/off rate of the template-monomer interaction is an indicator for the templates ability to induce repeat units in the main chain. ${ }^{73}$ Very few studies on how the template influences the initial stages of the polymerization have been reported. ${ }^{54,55}$ This warrants further studies in this regard. As we have shown in this report, a solution binding constant for the host monomer template interaction exceeding $7000 \mathrm{M}^{-1}$ is sufficient for achieving this. This contrasts with situations where the rate of propagation is slow with respect to the on/off rate. Here the template will have time to dissociate before the next monomer addition. In this case, imprinting follows the mechanism outlined in Figure $9 \mathrm{~b}$ where preformed polymer chains are conformationally stabilized by the template via multidentate interactions. Although this is likely the dominating mechanism in most noncovalent imprinting systems, ${ }^{16-20}$ studies of corresponding linear polymers can provide further important insights into the imprinting process.

\section{ASSOCIATED CONTENT}

\section{(s) Supporting Information}

The Supporting Information is available free of charge at https://pubs.acs.org/doi/10.1021/jacs.0c00707.

Experimental section outlining synthetic procedures, characterization techniques and data evaluation and dynamic simulations, and supporting tables and graphics (PDF)

\section{AUTHOR INFORMATION}

\section{Corresponding Author}

Börje Sellergren - Department of Biomedical Sciences, Faculty of Health and Society, Malmö University, 20506 Malmö, Sweden; Faculty of Chemistry, Technical University of Dortmund, 44227 Dortmund, Germany; (i) orcid.org/00000002-2392-3305; Email: borje.sellegren@mau.se

\section{Authors}

Sudhirkumar Shinde - Department of Biomedical Sciences, Faculty of Health and Society, Malmö University, 20506 Malmö, Sweden; Faculty of Chemistry, Technical University of Dortmund, 44227 Dortmund, Germany; 이이.org/00000001-9460-0936

Anil Incel - Department of Biomedical Sciences, Faculty of Health and Society, Malmö University, 20506 Malmö, Sweden

Mona Mansour - Department of Biomedical Sciences, Faculty of Health and Society, Malmö University, 20506 Malmö, Sweden

Gustaf D. Olsson - Bioorganic \& Biophysical Chemistry Laboratory, Linneaus University Center for Biomaterials Chemistry, Department of Chemistry \& Biomedical Sciences, Linnaeus University, 39182 Kalmar, Sweden

Ian A. Nicholls - Bioorganic \& Biophysical Chemistry Laboratory, Linneaus University Center for Biomaterials Chemistry, Department of Chemistry \& Biomedical Sciences, Linnaeus University, 39182 Kalmar, Sweden; 이이.org/ 0000-0002-0407-6542

Cem Esen - Faculty of Chemistry, Technical University of Dortmund, 44227 Dortmund, Germany

Javier Urraca - Faculty of Chemistry, Technical University of Dortmund, 44227 Dortmund, Germany

Complete contact information is available at:

https://pubs.acs.org/10.1021/jacs.0c00707

\section{Author Contributions}

OThese authors contributed equally. The manuscript was written through contributions of all authors. All authors have given approval to the final version of the manuscript.

\section{Funding}

Marie Skłodowska-Curie Actions PITN-GA-2010-264699 and H2020-MSCA-ETN-2016, 722171; Swedish Vetenskapsrådet (VR) under grant number 2014-3794; Sweden KnowledgeFoundation (KKS) for research under project number 20150086. Deutsche Forschungsgemeinsc haft (DFG) (Se 777/9-1).

\section{Notes}

The authors declare no competing financial interest.

\section{ACKNOWLEDGMENTS}

We gratefully acknowledge financial support from the Marie Skłodowska-Curie Actions (PITN-GA-2010-264699 and H2020-MSCA-ITN-2016, 722171), Vetenskapsrådet (VR) under grant number 2014-3794, the Deutsche Forschungsgemeinschaft (DFG) under grant number Se 777/9-1 and the Sweden and the Sweden Knowledge-Foundation (KKS) for research under project number 20150086. S.S. gratefully acknowledges a Matching Funds fellowship from the Deutsche Akademische Austauschdienst (DAAD). C.E. is grateful for the postdoctoral research fellowship from the Council of Higher Education in Turkey (YÖK) and for the visiting academic funding from the German Academic Exchange Service (DAAD).

\section{REFERENCES}

(1) Langton, M. J.; Serpell, C. J.; Beer, P. D. Anion Recognition in Water: Recent Advances from a Supramolecular and Macromolecular Perspective. Angew. Chem., Int. Ed. 2016, 55 (6), 1974-1987.

(2) Kubik, S. Supramolecular Chemistry in Water; Wiley-VCH, 2019; p 244. 
(3) Heymann, J. J.; Weaver, K. D.; Mietzner, T. A.; Crumbliss, A. L. Sulfate as a Synergistic Anion Facilitating Iron Binding by the Bacterial Transferrin FbpA: The Origins and Effects of Anion Promiscuity. J. Am. Chem. Soc. 2007, 129 (31), 9704-9712.

(4) Hargrove, A. E.; Nieto, S.; Zhang, T.; Sessler, J. L.; Anslyn, E. V. Artificial Receptors for the Recognition of Phosphorylated Molecules. Chem. Rev. 2011, 111 (11), 6603-6782.

(5) Ravikumar, I.; Ghosh, P. Recognition and separation of sulfate anions. Chem. Soc. Rev. 2012, 41 (8), 3077-3098.

(6) Fowler, C. J.; Haverlock, T. J.; Moyer, B. A.; Shriver, J. A.; Gross, D. E.; Marquez, M.; Sessler, J. L.; Hossain, M. A.; Bowman-James, K. Enhanced anion exchange for selective sulfate extraction: overcoming the Hofmeister bias. J. Am. Chem. Soc. 2008, 130 (44), 14386-14387.

(7) Sommer, F.; Kubik, S. Anion binding of a neutral bis(cyclopeptide) in water-methanol mixtures containing up to $95 \%$ water. Org. Biomol. Chem. 2014, 12 (44), 8851-8860.

(8) Liu, W.-X.; Jiang, Y.-B. Intramolecular Hydrogen Bonding and Anion Binding of N-Benzamido- $\mathrm{N}^{\prime}$-benzoylthioureas. J. Org. Chem. 2008, 73 (3), 1124-1127.

(9) Duke, R. M.; O’Brien, J. E.; McCabe, T.; Gunnlaugsson, T. Colorimetric sensing of anions in aqueous solution using a charge neutral, cleft-like, amidothiourea receptor: tilting the balance between hydrogen bonding and deprotonation in anion recognition. Org. Biomol. Chem. 2008, 6 (22), 4089-4092.

(10) Ravikumar, I.; Lakshminarayanan, P. S.; Arunachalam, M.; Suresh, E.; Ghosh, P. Anion complexation of a pentafluorophenylsubstituted tripodal urea receptor in solution and the solid state: selectivity toward phosphate. Dalton Transactions 2009, No. 21, $4160-4168$

(11) Emami Khansari, M.; Mirchi, A.; Pramanik, A.; Johnson, C.; Leszczynski, J.; Hossain, M. Remarkable hexafunctional anion receptor with operational urea-based inner cleft and thiourea-based outer cleft: Novel design with high-efficiency for sulfate binding. Sci. Rep. 2017, 7 DOI: 10.1038/s41598-017-05831-x.

(12) Jin, C.; Zhang, M.; Wu, L.; Guan, Y.; Pan, Y.; Jiang, J.; Lin, C.; Wang, L. Squaramide-based tripodal receptors for selective recognition of sulfate anion. Chem. Commun. 2013, 49 (20), 2025-2027.

(13) Busschaert, N.; Elmes, R. B. P.; Czech, D. D.; Wu, X.; Kirby, I. L.; Peck, E. M.; Hendzel, K. D.; Shaw, S. K.; Chan, B.; Smith, B. D.; Jolliffe, K. A.; Gale, P. A. Thiosquaramides: $\mathrm{pH}$ switchable anion transporters. Chemical Science 2014, 5 (9), 3617-3626.

(14) Qin, L.; Wright, J. R.; Lane, J. D. E.; Berry, S. N.; Elmes, R. B. P.; Jolliffe, K. A. Receptors for sulfate that function across a wide $\mathrm{pH}$ range in mixed aqueous-DMSO media. Chem. Commun. 2019, 55 (82), 12312-12315.

(15) Whitcombe, M. J.; Kirsch, N.; Nicholls, I. A. Molecular imprinting science and technology: a survey of the literature for the years 2004-2011. J. Mol. Recognit. 2014, 27 (6), 297-401.

(16) Chen, L.; Wang, X.; Lu, W.; Wu, X.; Li, J. Molecular imprinting: perspectives and applications. Chem. Soc. Rev. 2016, 45 (8), 2137-2211.

(17) Haupt, K.; Ayela, C. Molecular Imprinting; Springer, 2012.

(18) Sellergren, B.; Hall, A. J., Molecularly Imprinted Polymers. In Supramolecular Chemistry: from Molecules to Nanomaterials; Steed, J. W., Gale, P. A., Eds.; John Wiley \& Sons, Ltd: Chichester, UK, 2012; pp 3255-3282.

(19) Takeuchi, T.; Hayashi, T.; Ichikawa, S.; Kaji, A.; Masui, M.; Matsumoto, H.; Sasao, R. Molecularly Imprinted Tailor-Made Functional Polymer Receptors for Highly Sensitive and Selective Separation and Detection of Target Molecules. Chromatography 2016, 37 (2), 43-64.

(20) Cheong, W. J.; Yang, S. H.; Ali, F. Molecular imprinted polymers for separation science: A review of reviews. J. Sep. Sci. 2013, 36 (3), 609-628.

(21) Wierzbicka, C.; Liu, M.; Bauer, D.; Irgum, K.; Sellergren, B. Cationic $\mathrm{pTyr} / \mathrm{pSer}$. imprinted polymers based on a bis-imidazolium host monomer: phosphopeptide recognition in aqueous buffers demonstrated by $\mu$-liquid chromatography and monolithic columns. J. Mater. Chem. B 2017, 5 (5), 953-960.
(22) Sulc, R.; Szekely, G.; Shinde, S.; Wierzbicka, C.; Vilela, F.; Bauer, D.; Sellergren, B. Phospholipid imprinted polymers as selective endotoxin scavengers. Sci. Rep. 2017, 7, 44299.

(23) Liu, M.; Torsetnes, S. B.; Wierzbicka, C.; Jensen, O. N.; Sellergren, B.; Irgum, K. Selective Enrichment of Phosphorylated Peptides by Monolithic Polymers Surface Imprinted with bisImidazolium Moieties by UV-Initiated Cryopolymerization. Anal. Chem. 2019, 91 (15), 10188-10196.

(24) Wulff, G.; Gross, T.; Schönfeld, R. Enzyme models based on molecularly imprinted polymers with strong esterase activity. Angew. Chem., Int. Ed. Engl. 1997, 36, 1962-9164.

(25) Wulff, G.; Knorr, K. Stoichiometric imprinting. Bioseparation 2001, 10, 257.

(26) Cutivet, A.; Schembri, C.; Kovensky, J.; Haupt, K. Molecularly Imprinted Microgels as Enzyme Inhibitors. J. Am. Chem. Soc. 2009, 131 (41), 14699-14702.

(27) Ambrosini, S.; Beyazit, S.; Haupt, K.; Tse Sum Bui, B. Solidphase synthesis of molecularly imprinted nanoparticles for protein recognition. Chem. Commun. 2013, 49 (60), 6746-6748.

(28) Emgenbroich, M.; Borrelli, C.; Shinde, S.; Lazraq, I.; Vilela, F.; Hall, A. J.; Oxelbark, J.; De Lorenzi, E.; Courtois, J.; Simanova, A.; Verhage, J.; Irgum, K.; Karim, K.; Sellergren, B. A PhosphotyrosineImprinted Polymer Receptor for the Recognition of Tyrosine Phosphorylated Peptides. Chem. - Eur. J. 2008, 14, 9516-9529.

(29) Shinde, S.; Bunschoten, A.; Kruijtzer, J. A. W.; Liskamp, R. M. J.; Sellergren, B. Imprinted Polymers Displaying High Affinity for Sulfated Protein Fragments. Angew. Chem., Int. Ed. 2012, 51 (33), $8326-8329$

(30) Wan, W.; Biyikal, M.; Wagner, R.; Sellergren, B.; Rurack, K. Fluorescent Sensory Microparticles that "Light-up" Consisting of a Silica Core and a Molecularly Imprinted Polymer (MIP) Shell. Angew. Chem., Int. Ed. 2013, 52 (27), 7023-7027.

(31) Shinde, S.; El-Schich, Z.; Malakpour, A.; Wan, W.; Dizeyi, N.; Mohammadi, R.; Rurack, K.; Gjörloff Wingren, A.; Sellergren, B. Sialic acid imprinted fluorescent core-shell particles for selective labeling of cell surface glycans. J. Am. Chem. Soc. 2015, 137, 13908-13912.

(32) Kugimiya, A.; Takei, H. Selectivity and recovery performance of phosphate-selective molecularly imprinted polymer. Anal. Chim. Acta 2008, 606 (2), 252-256.

(33) Manesiotis, P.; Riley, A.; Bollen, B. Polymerisable squaramide receptors for anion binding and sensing. J. Mater. Chem. C 2014, 2 (42), 8990-8995.

(34) Lübke, C.; Lübke, M.; Whitcombe, M. J.; Vulfson, E. N. Imprinted polymers prepared with stoichiometric template-monomer complexes: Efficient binding of ampicillin from aqueous solutions. Macromolecules 2000, 33, 5098-5105.

(35) Manesiotis, P.; Hall, A. J.; Emgenbroich, M.; Quaglia, M.; De Lorenzi, E.; Sellergren, B. An enantioselective imprinted receptor for Z-glutamate exhibiting a binding induced color change. Chem. Commun. 2004, 2278-2279.

(36) Urraca, J. L.; Hall, A. J.; Moreno-Bondi, M. C.; Sellergren, B. A Stoichiometric Molecularly Imprinted Polymer for the Class-Selective Recognition of Antibiotics in Aqueous Media. Angew. Chem., Int. Ed. 2006, 45, 5158-5161.

(37) Urraca, J. L.; Aureliano, C. S. A.; Schillinger, E.; Esselmann, H.; Wiltfang, J.; Sellergren, B. Polymeric Complements to the Alzheimer's Disease Biomarker $\beta$-Amyloid Isoforms $A \beta 1-40$ and $A \beta 1-42$ for Blood Serum Analysis under Denaturing Conditions. J. Am. Chem. Soc. 2011, 133 (24), 9220-9223.

(38) Fan, E.; Van Arman, S. A.; Kincaid, S.; Hamilton, A. D. Moleclar recognition: Hydrogen bonding receptors that function in highly competitive solvents. J. Am. Chem. Soc. 1993, 115, 369-370.

(39) Gomez, D. E.; Fabbrizzi, L.; Licchelli, M.; Monzani, E. Urea vs. thiourea in anion recognition. Org. Biomol. Chem. 2005, 3, 14951500.

(40) Pérez-Casas, C.; Yatsimirsky, A. K. Detailing Hydrogen Bonding and Deprotonation Equilibria between Anions and Urea/ Thiourea Derivatives. J. Org. Chem. 2008, 73 (6), 2275-2284. 
(41) Wan, W.; Descalzo, A. B.; Shinde, S.; Weißhoff, H.; Orellana, G.; Sellergren, B.; Rurack, K. Ratiometric Fluorescence Detection of Phosphorylated Amino Acids Through Excited-State Proton Transfer by Using Molecularly Imprinted Polymer (MIP) Recognition Nanolayers. Chem. - Eur. J. 2017, 23 (63), 15974-15983.

(42) Wagner, S.; Zapata, C.; Wan, W.; Gawlitza, K.; Weber, M.; Rurack, K. Role of Counterions in Molecularly Imprinted Polymers for Anionic Species. Langmuir 2018, 34 (23), 6963-6975.

(43) Kelly, T. R.; Kim, M. H. Relative binding affinity of carboxylate and its isoteres: Nitro, phosphoate, phosphonate, sulfonate and dlactone. J. Am. Chem. Soc. 1994, 116, 7072-7080.

(44) Boiocchi, M.; Del Boca, L.; Gómez, D. E.; Fabbrizzi, L.; Licchelli, M.; Monzani, E. Nature of Urea-Fluoride Interaction: Incipient and Definitive Proton Transfer. J. Am. Chem. Soc. 2004, 126 (50), 16507-16514.

(45) Karlsson, B. C.; O’Mahony, J.; Karlsson, J. G.; Bengtsson, H.; Eriksson, L. A.; Nicholls, I. A. Structure and dynamics of monomertemplate complexation: an explanation for molecularly imprinted polymer recognition site heterogeneity. J. Am. Chem. Soc. 2009, 131 (37), 13297-304.

(46) Shoravi, S.; Olsson, G. D.; Karlsson, B. C.; Nicholls, I. A. On the influence of crosslinker on template complexation in molecularly imprinted polymers: a computational study of prepolymerization mixture events with correlations to template-polymer recognition behavior and NMR spectroscopic studies. Int. J. Mol. Sci. 2014, 15 (6), 10622-34.

(47) Golker, K.; Karlsson, B. C. G.; Olsson, G. D.; Rosengren, A. M.; Nicholls, I. A. Influence of Composition and Morphology on Template Recognition in Molecularly Imprinted Polymers. Macromolecules 2013, 46 (4), 1408-1414.

(48) Olsson, G. D.; Niedergall, K.; Bach, M.; Karlsson, B. C. G.; Tovar, G.; Nicholls, I. A. Simulation of imprinted emulsion prepolymerization mixtures. Polym. J. 2015, 47 (12), 827-830.

(49) Pramanik, A.; Thompson, B.; Hayes, T.; Tucker, K.; Powell, D. R.; Bonnesen, P. V.; Ellis, E. D.; Lee, K. S.; Yu, H.; Hossain, M. A. Seven-coordinate anion complex with a tren-based urea: Binding discrepancy of hydrogen sulfate in solid and solution states. Org. Biomol. Chem. 2011, 9 (12), 4444-4447.

(50) Shimizu, K. D. Binding isotherms. In Molecularly Imprinted Materials: Science and Technology 2004, 419-434.

(51) Busschaert, N.; Caltagirone, C.; Van Rossom, W.; Gale, P. A. Applications of Supramolecular Anion Recognition. Chem. Rev. 2015, 115 (15), 8038-8155.

(52) Vaughan, A. D.; Sizemore, S. P.; Byrne, M. E. Enhancing molecularly imprinted polymer binding properties via controlled/ living radical polymerization and reaction analysis. Polymer 2007, 48 (1), 74-81.

(53) Yungerman, I.; Srebnik, S. Factors Contributing to Binding-Site Imperfections in Imprinted Polymers. Chem. Mater. 2006, 18 (3), 657-663.

(54) Lanza, F.; Ruther, M.; Hall, A.J.; Dauwe, C.; Sellergren, B. Studies on the Process of formation, Nature and Stability of Binding Sites in Molecularly Imprinted Polymers. Mater. Res. Soc. Symp. Proc. 2002, 723, 1-11.

(55) Wulff, G.; Hohn, J. Chirality of polyvinyl compounds. 2. An asymmetric copolymerization. Macromolecules 1982, 15 (5), 125561.

(56) Pasini, D.; Takeuchi, D. Cyclopolymerizations: Synthetic Tools for the Precision Synthesis of Macromolecular Architectures. Chem. Rev. 2018, 118 (18), 8983-9057.

(57) Połowiński, S. Template polymerisation and co-polymerisation. Prog. Polym. Sci. 2002, 27 (3), 537-577.

(58) Chapiro, A. Auto-acceleration in free radical polymerizations caused by oriented monomer-polymer association complexes. Pure Appl. Chem. 1981, 53, 643-655.

(59) Giordanengo, R.; Viel, S.; Hidalgo, M.; Allard-Breton, B.; Thévand, A.; Charles, L. Analytical strategy for the molecular weight determination of random copolymers of poly(methyl methacrylate) and poly(methacrylic acid). J. Am. Soc. Mass Spectrom. 2010, 21 (6), $1075-1085$

(60) Diehl, B., Chapter 2 - NMR Applications for Polymer Characterisation. In NMR Spectroscopy in Pharmaceutical Analysis; Holzgrabe, U., Wawer, I., Diehl, B., Eds.; Elsevier: Amsterdam, 2008; pp 157-180.

(61) Terashima, T.; Kawabe, M.; Miyabara, Y.; Yoda, H.; Sawamoto, M. Polymeric pseudo-crown ether for cation recognition via cation template-assisted cyclopolymerization. Nat. Commun. 2013, 4 (1), 2321.

(62) Kim, S. K.; Sessler, J. L. Ion pair receptors. Chem. Soc. Rev. 2010, 39 (10), 3784-3809.

(63) Shinde, S.; Mansour, M.; Incel, A.; Mavliutova, L.; Wierzbicka, C.; Sellergren, B. High salt compatible oxyanion receptors by dual ion imprinting. Chem. Sci. 2020, 11 (16), 4246-4250.

(64) Sellergren, B.; Shea, K. J. On the influence of polymer morphology on the ability of imprinted polymers to separate enantiomers. J. Chromatogr. 1993, 635, 31.

(65) Shea, K. J.; Sasaki, D. Y. An analysis of small molecule binding to functionalized synthetic polymers by $13 \mathrm{C} \mathrm{CP} / \mathrm{MAS}$ NMR and FTIR spectroscopy. J. Am. Chem. Soc. 1991, 113, 4109-4120.

(66) Shea, K. J.; Sasaki, D. Y. On the Control of Microenvironment Shape of Functionalized Network Polymers Prepared by Template Polymerization. J. Am. Chem. Soc. 1989, 111, 3442-3444.

(67) Skogsberg, U.; Meyer, C.; Rehbein, J.; Fischer, G.; Schauff, S.; Welsch, N.; Albert, K.; Hall, A. J.; Sellergren, B. A solid-state and suspended-state magic angle spinning nuclear magnetic resonance spectroscopic investigation of a 9-ethyladenine molecularly imprinted polymer. Polymer 2007, 48, 229-238.

(68) O’Mahony, J.; Molinelli, A.; Nolan, K.; Smyth, M. R.; Mizaikoff, B. Anatomy of a successful imprint: Analysing the recognition mechanisms of a molecularly imprinted polymer for quercetin. Biosens. Bioelectron. 2006, 21 (7), 1383-1392.

(69) Molinelli, A.; O’Mahony, J.; Nolan, K.; Smyth, M. R.; Jakusch, M.; Mizaikoff, B. Analyzing the Mechanisms of Selectivity in Biomimetic Self-Assemblies via IR and NMR Spectroscopy of Prepolymerization Solutions and Molecular Dynamics Simulations. Anal. Chem. 2005, 77 (16), 5196-5204.

(70) Kostrewa, S.; Emgenbroich, M.; Klockow, D.; Wulff, G. Surface-enhanced Raman scattering on molecularly imprinted polymers in water. Macromol. Chem. Phys. 2003, 204 (3), 481-487.

(71) Shea, K. J.; Sasaki, D. Y.; Stoddard, G. J. Fluorescence probes for evaluating chain solvation in network polymers. An analysis of the solvatochromic shift of the dansyl probe in macroporous styrenedivinylbenzene and styrene-diisopropenylbenzene copolymers. Macromolecules 1989, 22, 1722-1730.

(72) Svenson, J.; Andersson, H. S.; Piletsky, S. A.; Nicholls, I. A. Spectroscopic studies of the molecular imprinting self-assembly process. J. Mol. Recognit. 1998, 11 (1-6), 83-86.

(73) Sellergren, B.; Hall, A. J. Fundamental aspects on the synthesis and characterization of imprinted network polymers. In Molecularly Imprinted Polymers. Man-Made Mimics of Antibodies and Their Applications in Analytical Chemistry; Sellergren, B., Ed.; Elesevier Science B.V.: Amsterdam, 2001; Vol. 23, pp 21-57. 